\title{
Guajavadimer A, a dimeric caryophyllene-derived meroterpenoid with a new carbon skeleton from the leaves of Psidium guajava.
}

Chuang-Jun Li, Jie Ma, Hua Sun, Dan Zhang, and Dong-Ming Zhang*

State Key Laboratory of Bioactive Substance and Function of Natural Medicines, Institute of Materia Medica, Chinese Academy of Medical Sciences and Peking Union Medical College, Beijing 100050, People's Republic of China.

*Corresponding author. E-mail: zhangdm@imm.ac.cn; Fax/Tel: +86-01063165227 


\section{Supporting Information}

\section{Table of contents}

1. General experimental procedures

2. Plant material

3. Extraction and isolation

4. Physico-chemical constant of guajavadimer A (1)

5. Single crystal X-ray data and structure of guajavadimer A (1)

Table S1 X-ray crystallographic data for guajavadimer A (1)

Figure S1. X-ray crystal structure of guajavadimer A (1).

6. Hepatoprotective activity assay

Table S2 Hepatoprotective effect of compound $1(10 \mu \mathrm{M})$ against APAP-induced toxicity in HepG2 cell.

7. PTP1B activity assay

Figure S2. The UV spectrum of guajavadimer A (1) in $\mathrm{CH}_{3} \mathrm{OH}$.

Figure S3. The IR spectrum of guajavadimer A(1).

Figure S4. The HR-ESI-MS spectrum of guajavadimer A(1)

Figure S5. The HR-ESI-MS spectrum of guajavadimer A (1)

Figure S6. The ${ }^{1} \mathrm{H}$ NMR spectrum of guajavadimer $\mathrm{A}(\mathbf{1})$ in $\mathrm{CDCl}_{3}(600 \mathrm{MHz})$.

Figure S7. The ${ }^{1} \mathrm{H}$ NMR spectrum of guajavadimer $\mathrm{A}(\mathbf{1})$ in $\mathrm{CDCl}_{3}(600 \mathrm{MHz})$.

Figure S8. The ${ }^{1} \mathrm{H}$ NMR spectrum of guajavadimer $\mathrm{A}(\mathbf{1})$ in $\mathrm{CDCl}_{3}(600 \mathrm{MHz})$.

Figure S9. The ${ }^{13} \mathrm{C}$ NMR spectrum of guajavadimer $\mathrm{A}(\mathbf{1})$ in $\mathrm{CDCl}_{3}(150 \mathrm{MHz})$.

Figure $\mathrm{S} 10$ The ${ }^{13} \mathrm{C}$ NMR spectrum of guajavadimer $\mathrm{A}(1)$ in $\mathrm{CDCl}_{3}(150 \mathrm{MHz})$.

Figure $\mathrm{S} 11$ The ${ }^{13} \mathrm{C}$ NMR spectrum of guajavadimer $\mathrm{A}(\mathbf{1})$ in $\mathrm{CDCl}_{3}(150 \mathrm{MHz})$.

Figure S12. The DEPT spectrum of guajavadimer A (1) in $\mathrm{CDCl}_{3}(150 \mathrm{MHz})$.

Figure S13 The DEPT spectrum of guajavadimer $\mathrm{A}(\mathbf{1})$ in $\mathrm{CDCl}_{3}(150 \mathrm{MHz})$.

Figure S14. The DEPT spectrum of guajavadimer A (1) in $\mathrm{CDCl}_{3}(150 \mathrm{MHz})$.

Figure $\mathrm{S} 15$ The ${ }^{1} \mathrm{H}-{ }^{1} \mathrm{H}$ COSY spectrum of guajavadimer $\mathrm{A}(\mathbf{1})$ in $\mathrm{CDCl}_{3}(600 \mathrm{MHz})$.

Figure $\mathrm{S} 16$. The ${ }^{1} \mathrm{H}-{ }^{1} \mathrm{H}$ COSY spectrum of guajavadimer $\mathrm{A}(\mathbf{1})$ in $\mathrm{CDCl}_{3}(600 \mathrm{MHz})$.

Figure $\mathrm{S} 17$. The ${ }^{1} \mathrm{H}-{ }^{1} \mathrm{H}$ COSY spectrum of guajavadimer $\mathrm{A}(\mathbf{1})$ in $\mathrm{CDCl}_{3}(600 \mathrm{MHz})$. 
Figure S18. The HSQC spectrum of guajavadimer A (1) in $\mathrm{CDCl}_{3}(600 \mathrm{MHz})$.

Figure S19. The HSQC spectrum of guajavadimer A (1) in $\mathrm{CDCl}_{3}(600 \mathrm{MHz})$.

Figure S20. The HSQC spectrum of guajavadimer A (1) in $\mathrm{CDCl}_{3}(600 \mathrm{MHz})$.

Figure S21. The HMBC spectrum of guajavadimer $\mathrm{A}(\mathbf{1})$ in $\mathrm{CDCl}_{3}(600 \mathrm{MHz})$.

Figure S22. The HMBC spectrum of guajavadimer A (1) in $\mathrm{CDCl}_{3}(600 \mathrm{MHz})$.

Figure S23. The HMBC spectrum of guajavadimer $\mathrm{A}(\mathbf{1})$ in $\mathrm{CDCl}_{3}(600 \mathrm{MHz})$.

Figure S24. The HMBC spectrum of guajavadimer $\mathrm{A}(1)$ in $\mathrm{CDCl}_{3}(600 \mathrm{MHz})$.

Figure S25. The HMBC spectrum of guajavadimer A (1) in $\mathrm{CDCl}_{3}(600 \mathrm{MHz})$.

Figure S26. The HMBC spectrum of guajavadimer A (1) in $\mathrm{CDCl}_{3}(600 \mathrm{MHz})$.

Figure S27. The HMBC spectrum of guajavadimer $\mathrm{A}(1)$ in $\mathrm{CDCl}_{3}(600 \mathrm{MHz})$.

Figure S28. The HMBC spectrum of guajavadimer A (1) in $\mathrm{CDCl}_{3}(600 \mathrm{MHz})$.

Figure S29. The NOESY spectrum of guajavadimer A (1) in $\mathrm{CDCl}_{3}(600 \mathrm{MHz})$.

Figure S30. The NOESY spectrum of guajavadimer A (1) in $\mathrm{CDCl}_{3}(600 \mathrm{MHz})$.

Figure S31. The TOCSY spectrum of guajavadimer $\mathrm{A}(\mathbf{1})$ in $\mathrm{CDCl}_{3}(600 \mathrm{MHz})$

Figure S32. The TOCSY spectrum of guajavadimer A (1) in $\mathrm{CDCl}_{3}(600 \mathrm{MHz})$

Figure S33. The ROESY spectrum of guajavadimer A (1) in $\mathrm{CDCl}_{3}(600 \mathrm{MHz})$.

Figure S34. The ROESY spectrum of guajavadimer $\mathrm{A}(\mathbf{1})$ in $\mathrm{CDCl}_{3}(600 \mathrm{MHz})$.

Figure S35. The ROESY spectrum of guajavadimer $\mathrm{A}(\mathbf{1})$ in $\mathrm{CDCl}_{3}(600 \mathrm{MHz})$.

Figure S36. The 1D-TOCSY spectrum of guajavadimer A (1) in $\mathrm{CDCl}_{3}(600 \mathrm{MHz})$

Figure S37. The 1D-TOCSY spectrum of guajavadimer A (1) in $\mathrm{CDCl}_{3}(600 \mathrm{MHz})$

Figure S38. The 1D-TOCSY spectrum of guajavadimer A (1) in $\mathrm{CDCl}_{3}(600 \mathrm{MHz})$

Figure S39. The 1D-TOCSY spectrum of guajavadimer A (1) in $\mathrm{CDCl}_{3}(600 \mathrm{MHz})$

Figure S40. The 1D-TOCSY spectrum of guajavadimer A (1) in $\mathrm{CDCl}_{3}(600 \mathrm{MHz})$ 


\section{General experimental produces.}

Melting point was measured on an $\mathrm{XT}_{4}-100$ melting instrument and uncorrected. Optical rotation was measured on a JASCO P-2000 polarimeter. UV spectrum was measured on a JASCO V650 spectrophotometer. IR spectrum was recorded on a Nicolet 5700 FT-IR microscope instrument (FT-IR microscope transmission). NMR spectra were acquired with VNS-600 spectrometers. HRESIMS spectrum was collected on an Agilent 1100 series LC/MSD ion trap mass spectrometer. Preparative HPLC was performed on a Shimadzu LC-6AD instrument with a SPD-20A detector, using an YMC-Pack ODS-A column $(20 \times 250 \mathrm{~mm}, 5 \mu \mathrm{m})$. Column chromatography was performed with silica gel (200-300 mesh, Qingdao Marine Chemical Inc., Qingdao, People's Republic of China) and ODS (50 $\mu \mathrm{m}$, YMC, Japan). TLC was carried out on glass precoated silica gel GF254 plates. Spots were visualized under UV light or by spraying with $10 \%$ sulfuric acid in EtOH followed by heating.

\section{Plant material.}

The leaves of Psidium guajava L. were collected in Guangxi, China, in September 2011. A voucher specimen (No. FL20110066) was identified by Professor Lin Ma from the Institute of Materia Medica, Chinese Academy of Medical Sciences and Peking Union Medical College and was deposited at the herbarium of the Institute of Material Medica, Chinese Academy of Medical Sciences and Peking Union Medical College, China.

\section{Extraction and isolation.}

Air-dried leaves of Psidium guajava L. $(20 \mathrm{~kg})$ were extracted with $80 \%$ ethanol $(200 \mathrm{~L} \times 2 \mathrm{~h} \times 2)$. After evaporation of $\mathrm{EtOH}$ in vacuo, the aqueous residue was diluted with water and then partitioned with $\mathrm{CHCl}_{3}(30 \mathrm{~L} \times 3)$. The $\mathrm{CHCl}_{3}$ extract (800 g) was subjected to column chromatography on silica gel with $\mathrm{CHCl}_{3}-\mathrm{MeOH}$ $(100: 0-5: 1)$ to afford 10 fractions $\left(A_{1}-A_{10}\right)$. Fraction $A_{1}(102 \mathrm{~g})$ was separated by a silica gel column $(200-300$ mesh, $10 \times 150 \mathrm{~cm})$ eluted with cyclohexane $-E t O A c$ (100:0-50:50, three time column volume for each gradient) to afford 20 fractions 
$\left(\mathrm{B}_{1}-\mathrm{B}_{20}\right)$. Subfraction $\mathrm{B}_{3}(13 \mathrm{~g})$ was separated by a silica gel column $(5 \times 50 \mathrm{~cm})$ using cyclohexane-EtOAc (95:5-70:30, three times of column volume for each gradient) as eluent to afford 10 fractions $\left(\mathrm{C}_{1}-\mathrm{C}_{10}\right)$. Fraction $\mathrm{C}_{3}(2.5 \mathrm{~g})$ was passed over an RP-18 column $(2.5 \times 50 \mathrm{~cm})$ with $\mathrm{MeOH}-$ water $(80-100 \%$, three times column volume for each gradient) to give 5 subfractions $\mathrm{C}_{3} \mathrm{a}-\mathrm{C}_{3} \mathrm{e}$. The fraction $\mathrm{C}_{3} \mathrm{~d}$ was purified by preparative HPLC $\left(8 \mathrm{~mL} / \mathrm{min}, \mathrm{t}_{\mathrm{R}} 48.5 \mathrm{~min}, 98 \% \mathrm{MeOH}\right.$, detected at $280 \mathrm{~nm}$; YMC-Pack ODS-A column $20 \times 250 \mathrm{~mm}, 5 \mu \mathrm{m})$ to give $1(15 \mathrm{mg})$.

\section{Physico-chemical constant of guajavadimer A (1)}

Guajavadimer A (1). colorless crystal (in $\mathrm{MeOH}: \mathrm{CHCl}_{3}$ ), mp 179-180 ${ }^{\circ} \mathrm{C},[\alpha]^{25}{ }^{-}$ $1.3\left(\mathrm{CHCl}_{3} ; c\right.$ 0.10); UV (MeOH) $\lambda_{\max }(\log \varepsilon): 203$ (3.67), 235 (3.34), 299 (3.30), 352 (2.64) nm; IR (KBr) $v_{\max } 3279,2938,1628,1493,1445,1287,1126,1025,774$, $630 \mathrm{~cm}^{-1}$; HR-ESI-MS m/z 929.4977 ([M - H] $]^{-}$, calcd for $\mathrm{C}_{61} \mathrm{H}_{70} \mathrm{O}_{8}$ : 929.4998).

\section{X-ray Crystallographic Analysis of guajavadimer A (1) (See Table SI)}

Colorless crystal of 1 was obtained from $\mathrm{MeOH}: \mathrm{CHCl}_{3}$. Crystal data was acquired on a Agilent Xcalibur Eos Gemini diffractometer employing graphite monochromated $\mathrm{Cu}-\mathrm{K} \alpha$ radiation $(\lambda=1.54184 \AA)$. The structure was solved by direct methods using SHELXS-97. The crystal structure of 1 was solved by direct methods (SHELXS-97), expanded using a difference Fourier technique, and refined by the SHELXS-97 program and the full-matrix least-squares calculations. All non-hydrogen atoms were refined anisotropically, and all of the hydrogen atoms were fixed at calculated positions. Crystallographic data (excluding structure factor tables) for $\mathbf{1}$ have been deposited at the Cambridge Crystallographic Data Center as supplementary publication (CCDC 1430940). Copies of the data can be obtained free of charge by application to CCDC, 12, Union Road, Cambridge CB21EZ, UK [Fax: (+44) $1223 \quad 336$ 033; e-mail: deposit@ccdc.cam.ac.uk].

Table S1 X-ray crystallographic data for guajavadimer A (1)

\begin{tabular}{ll}
\hline Empirical formula & $\mathrm{C}_{61} \mathrm{H}_{70} \mathrm{O}_{8} \cdot \mathrm{CHCl}_{3}$ \\
Formula weight & 1050.54 \\
Temperature/K & 100.9 \\
Crystal system & orthorhombic
\end{tabular}




\begin{tabular}{|c|c|}
\hline Space group & $\mathrm{P} 2{ }_{1} 2_{1} 2_{1}$ \\
\hline $\mathrm{a} / \AA$ & $10.3434(4)$ \\
\hline $\mathrm{b} / \AA$ & $17.0470(8)$ \\
\hline $\mathrm{c} / \AA$ & $30.5673(13)$ \\
\hline$\alpha /^{\circ}$ & 90.00 \\
\hline$\beta /{ }^{\circ}$ & 90.00 \\
\hline$\gamma /{ }^{\circ}$ & 90.00 \\
\hline Volume $/ \AA^{3}$ & $5389.8(4)$ \\
\hline $\mathrm{Z}$ & 4 \\
\hline$\rho_{\text {calc }} \mathrm{g} / \mathrm{cm}^{3}$ & 1.295 \\
\hline$\mu / \mathrm{mm}^{-1}$ & 1.987 \\
\hline $\mathrm{F}(000)$ & 2232.0 \\
\hline Crystal size $/ \mathrm{mm}^{3}$ & $0.5 \times 0.45 \times 0.4$ \\
\hline Radiation & $\operatorname{CuK} \alpha(\lambda=1.54184)$ \\
\hline $2 \Theta$ range for data collection $/{ }^{\circ}$ & 5.94 to 142.46 \\
\hline Index ranges & $-8 \leq \mathrm{h} \leq 12,-20 \leq \mathrm{k} \leq 18,-37 \leq 1 \leq 35$ \\
\hline Reflections collected & 19407 \\
\hline Independent reflections & $10218\left[\mathrm{R}_{\text {int }}=0.0286, \mathrm{R}_{\text {sigma }}=0.0441\right]$ \\
\hline Data/restraints/parameters & $10218 / 0 / 668$ \\
\hline Goodness-of-fit on $\mathrm{F}^{2}$ & 1.036 \\
\hline Final $R$ indexes $[\mathrm{I}>=2 \sigma(\mathrm{I})]$ & $\mathrm{R}_{1}=0.0480, \mathrm{wR}_{2}=0.1283$ \\
\hline Final $\mathrm{R}$ indexes [all data] & $\mathrm{R}_{1}=0.0512, \mathrm{wR}_{2}=0.1314$ \\
\hline Largest diff. peak/hole / e $\AA^{-3}$ & $0.51 /-0.50$ \\
\hline Flack parameter & $0.013(15)$ \\
\hline
\end{tabular}

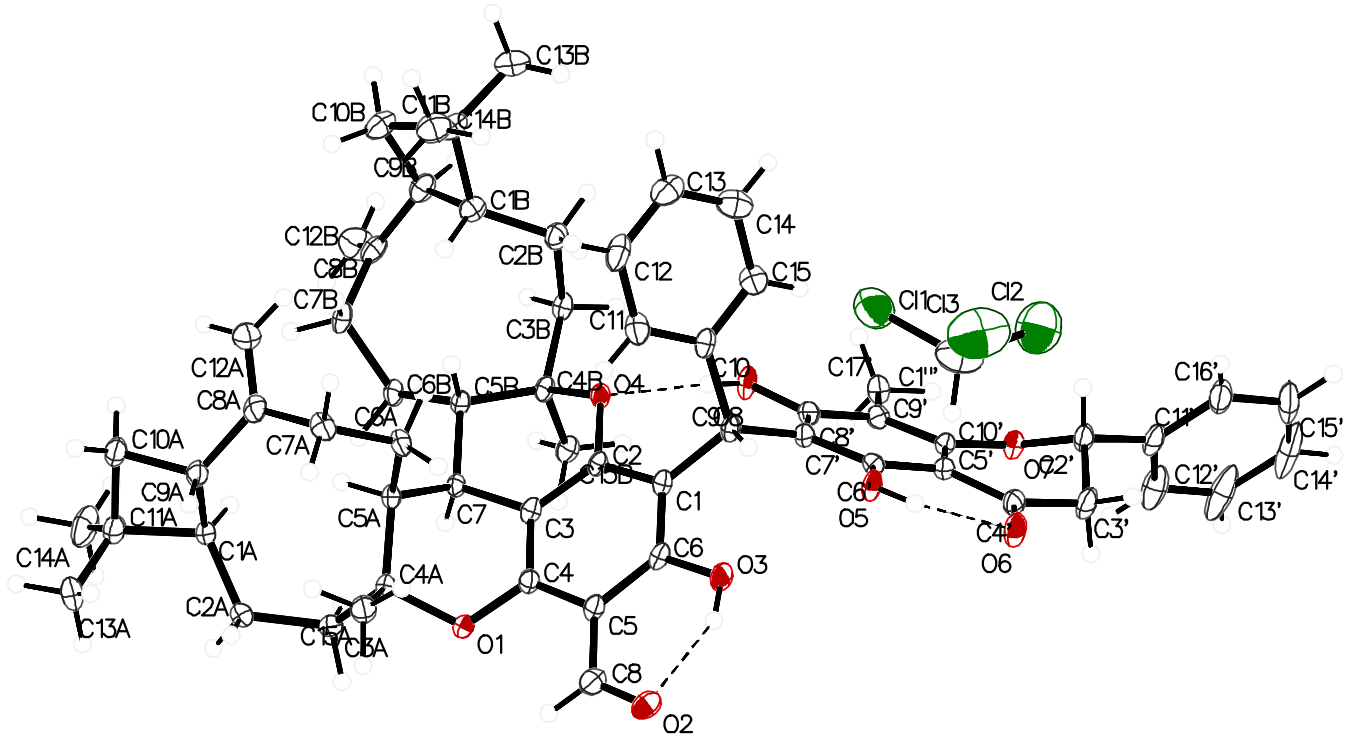


Figure S1. X-ray crystal structure of 1.

\section{Hepatoprotective activity assay}

Human HepG2 hepatoma cells were cultured in DMEM medium supplemented with 10\% fetal calf serum, $100 \mathrm{U} / \mathrm{mL}$ penicillin, and $100 \mu \mathrm{g} / \mathrm{mL}$ streptomycin at $37{ }^{\circ} \mathrm{C}$ in a humidified atmosphere of $5 \% \mathrm{CO}_{2}+95 \%$ air. The cells were then passaged by treatment with $0.25 \%$ trypsin in $0.02 \%$ EDTA. The MTT assay was used to assess the cytotoxicity of test samples. The cells were seeded in 96-well multiplates. After an overnight incubation at $37{ }^{\circ} \mathrm{C}$ with $5 \% \mathrm{CO}_{2}, 10 \mu \mathrm{m}$ test samples and APAP (final concentration of 8 $\mathrm{mM}$ ) were added into the wells and incubated for another $48 \mathrm{~h}$. Then $100 \mu \mathrm{L}$ of 0.5 $\mathrm{mg} / \mathrm{mL}$ MTT was added to each well after the withdrawal of the culture medium and incubated for an additional $4 \mathrm{~h}$. The resulting formazan was dissolved in $150 \mu \mathrm{L}$ of DMSO after aspiration of the culture medium. The plates were placed on a plate shaker for $30 \mathrm{~min}$ and read immediately at $570 \mathrm{~nm}$ using a microplate reader ${ }^{[10]}$.

Table S2 Hepatoprotective effect of compound $1(10 \mu \mathrm{M})$ against APAP-induced toxicity in HepG2 cell.

\begin{tabular}{llll}
\hline Compounds & OD (mean $\pm \mathrm{SD})$ & $\begin{array}{l}\text { Cell survival rate } \\
(\% \text { of normal) }\end{array}$ \\
\hline Control & $2.376 \pm 0.280$ & 100.00 \\
APAP 8mM & $1.451 \pm 0.114^{* * *}$ & 61.09 \\
$\mathbf{1}$ & $1.654 \pm 0.094^{\# \#}$ & 67.81 \\
Bicyclol $^{\text {a }}$ & $1.650 \pm 0.190^{\#}$ & 69.43 \\
\hline
\end{tabular}

${ }^{a}$ Positive control substance.

${ }^{* * *} P<0.001$, compared with control.

${ }^{\#} P<0.01$, compared with model (APAP)

${ }^{\#} P<0.05$, compared with model (APAP).

\section{PTP1 B activity assay ${ }^{[11]}$}

Recombinant human GST-PTP1B protein was over expressed by hGST-PTP1B-BL2 1 E. coli and purified by GST affinity chromatography. The reagent pNPP was used as substrate for the measurement of PTP1B activity. Compounds were pre-incubated with the enzyme at room temperature for $5 \mathrm{~min}$. Assay was performed in final volume of 100 
$\mu \mathrm{L}$ in the active system containing $50 \mathrm{Mm}$ HEPES, $5 \mathrm{mM}$ DTT, $150 \mathrm{mM} \mathrm{NaCl}, 2 \mathrm{mM}$ EDTA, and $2 \mathrm{mM}$ pNPP (pH 7.0), incubated at $30^{\circ} \mathrm{C}$ for $10 \mathrm{~min}$, stopped by addition of $50 \mu 13 \mathrm{M} \mathrm{NaOH}$. Then, the absorbance was determined at $405 \mathrm{~nm}$ wavelength. The similar system without GST-PTP1B protein was used as blank. The effects of compound $\mathbf{1}$ on PTP1B activity were measured, compound $\mathbf{1}$ not exhibited inhibit PTPIB activity, with a inhibition values of $1.3 \%$ at $10 \mu \mathrm{M}$. 
Figure S2. The UV spectrum of guajavadimer A (1).
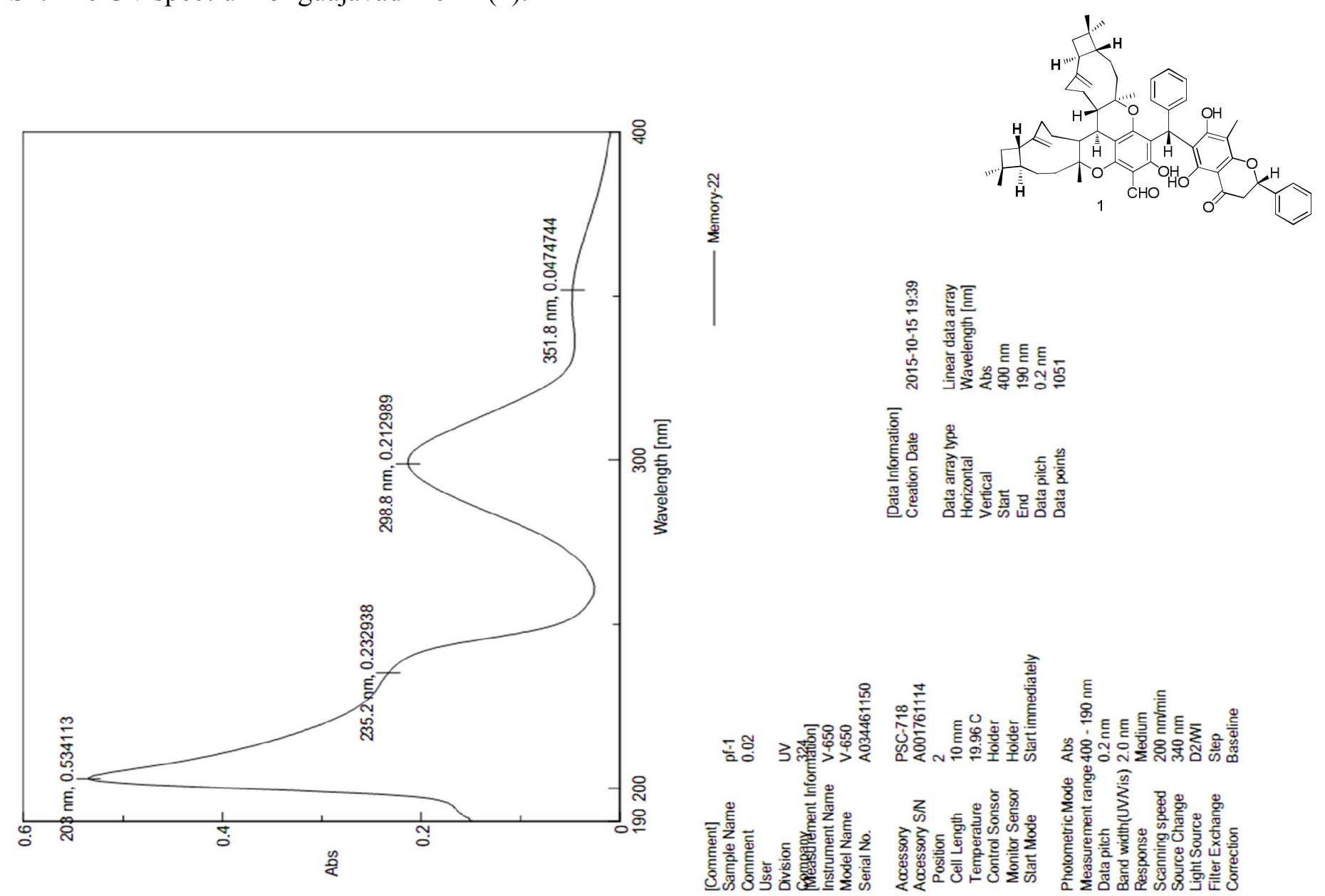

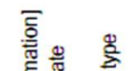

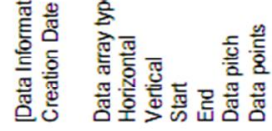

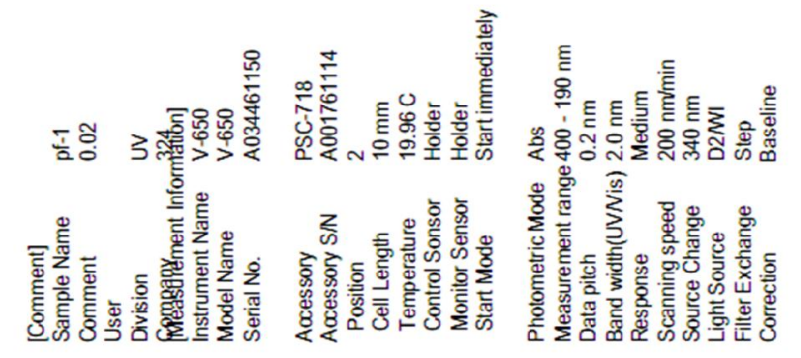


Figure S3. The IR spectrum of guajavadimer A (1).

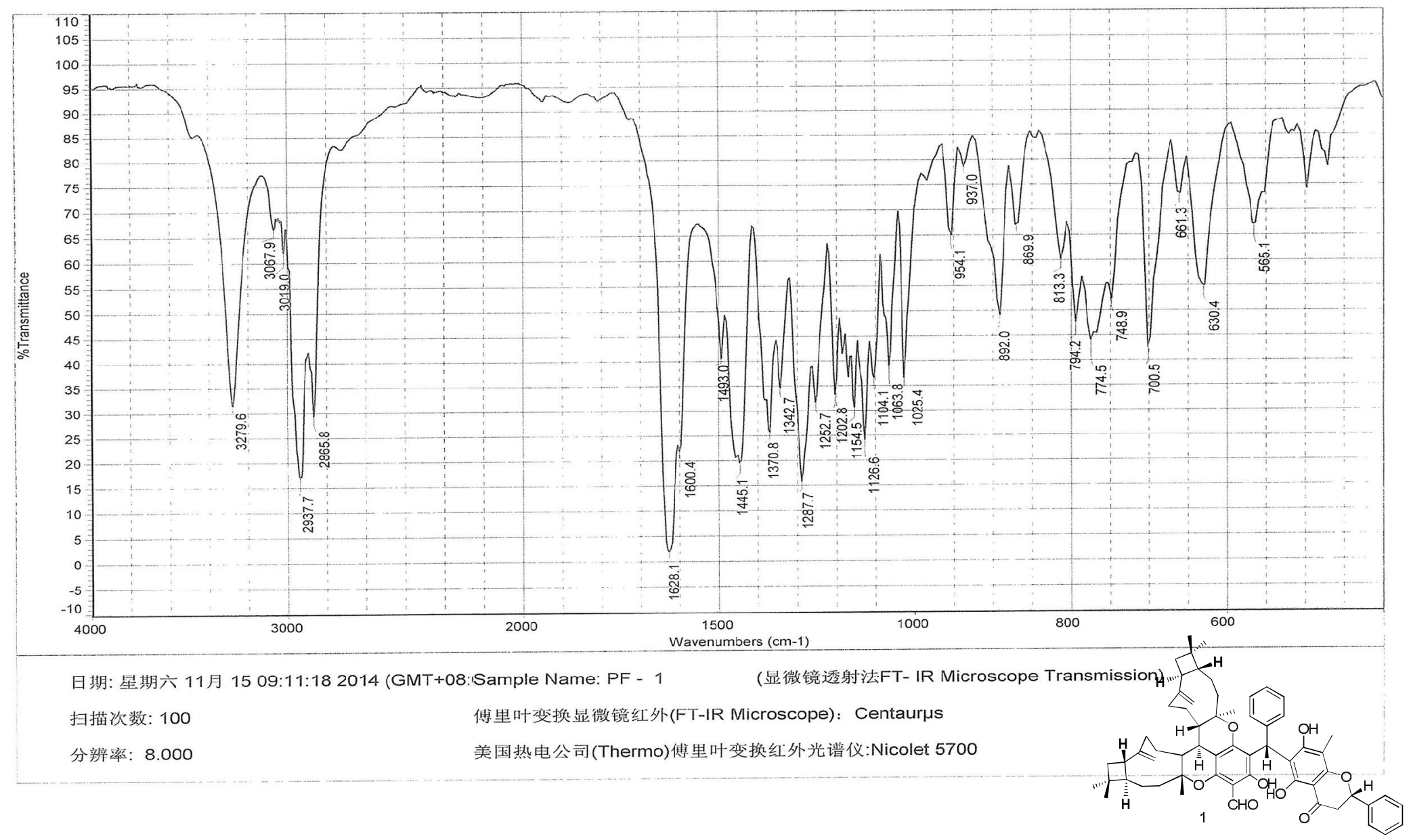


Figure S4. The HR-ESI-MS spectrum of guajavadimer A(1)

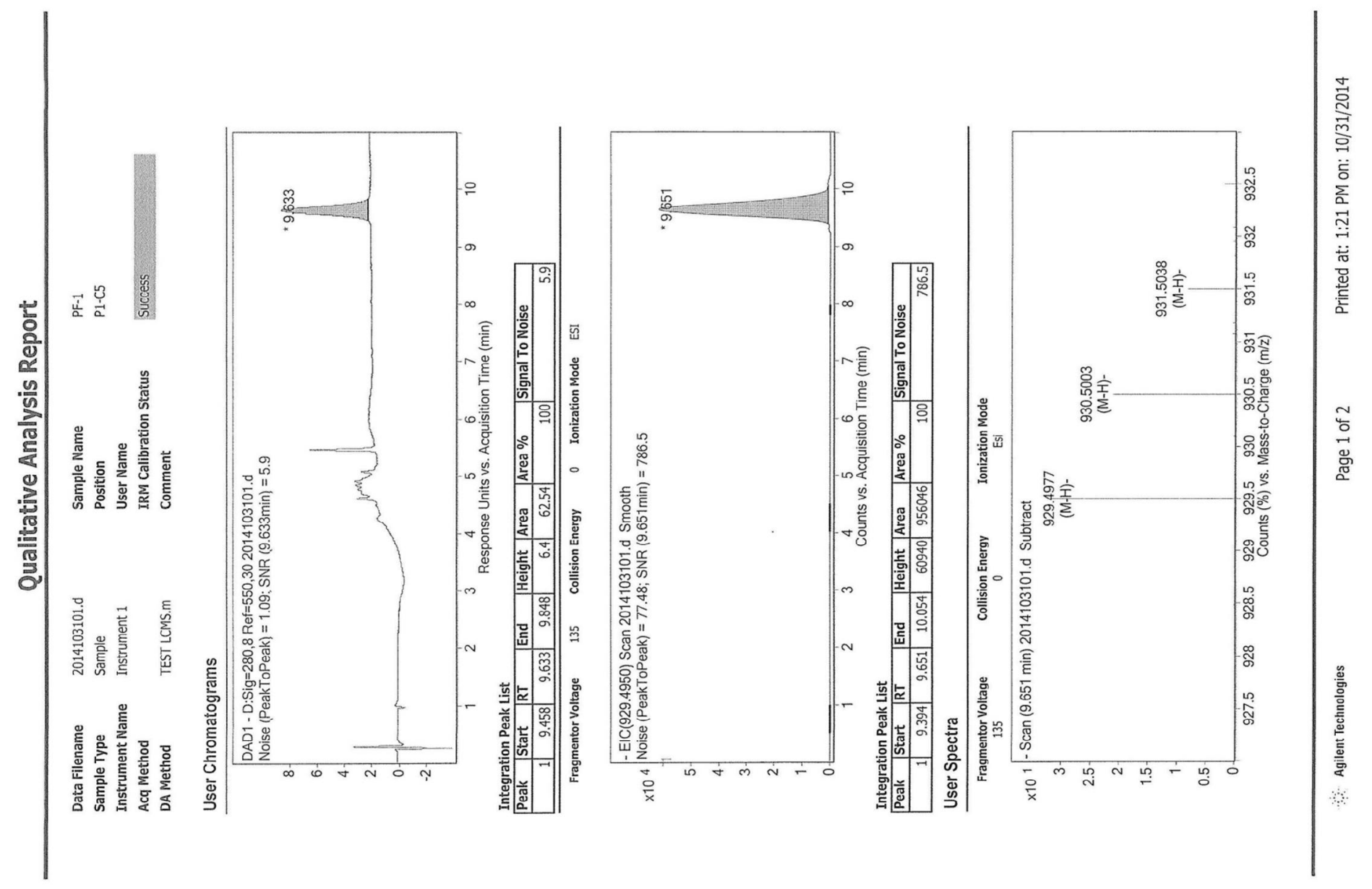


Figure S5. The HR-ESI-MS spectrum of guajavadimer A(1)

MS Formula Results: - Scan (9.651 min) Sub (2014103101.d)

\begin{tabular}{|c|c|c|c|c|c|c|c|c|c|c|c|c|c|}
\hline $\begin{array}{l}\mathrm{m} / \mathrm{z} \\
929.4977\end{array}$ & lon $\quad(M-H) \cdot$ & $\begin{array}{l}\text { Formula } \\
\text { C61 } 66908\end{array}$ & $\begin{array}{r}\text { Abundance } \\
622444\end{array}$ & & & & & & & & & & \\
\hline Best & Formula (M) & lon Formula & Score & Cross Sco & Mass & $\begin{array}{ll}\text { Calc Mass } \\
\end{array}$ & Calc $\mathrm{m} / 2$ & $\mid$\begin{tabular}{|l|l|} 
Ditf(popm) \\
\end{tabular} & Abs Liff( (ppm) & Mass Match & \begin{tabular}{|l|} 
Abund Match \\
\end{tabular} & \begin{tabular}{|c|} 
Spacing Match \\
\end{tabular} & DBE \\
\hline$\sqrt{v}$ & $\begin{array}{r}\text { C51 H70 O } \\
\end{array}$ & 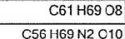 & 99.77 & & 930.5048 & & 929.4998 & 2.44 & 2.44 & 99.78 & 99.57 & & 27 \\
\hline & 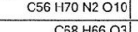 & C56HESN2 010 & $\frac{09.7}{90.24} \mid$ & & 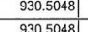 & $930.5033 \mid$ & 222.4458] & -1.9 & 1.9 & 99.87] & 99.17 & 90.98| & 23 \\
\hline 5 & C49 & C49H73N2015 & 98.74 & & 320.05068 & 93050290 & 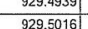 & -3.87| & $\frac{3.87}{441}$ & $\begin{array}{l}99.45 \\
9929 \\
\end{array}$ & $\begin{array}{c}98.63 \\
9672\end{array}$ & 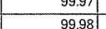 & 36 \\
\hline$F$ & C43 H778 021 & $\mathrm{C} 43 \mathrm{H} \mathrm{H7} 021$ & 97.61 & & 930.5048 & 930.5036 & 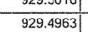 & $\begin{array}{c}-4.43] \\
-1.33]\end{array}$ & $\begin{array}{l}4.41 \\
1.33 \\
-13\end{array}$ & 99.294 & 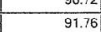 & 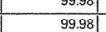 & $\frac{14}{5}$ \\
\hline
\end{tabular}

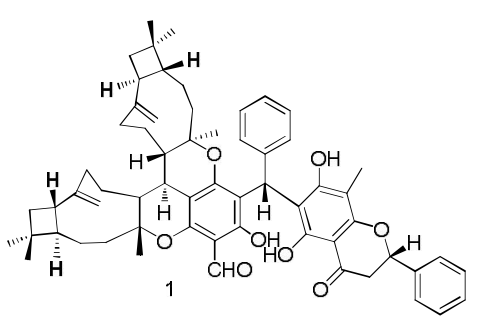


Figure S6. The ${ }^{1} \mathrm{H}$ NMR spectrum of guajavadimer A (1) in $\mathrm{CDCl}_{3}(600 \mathrm{MHz})$.

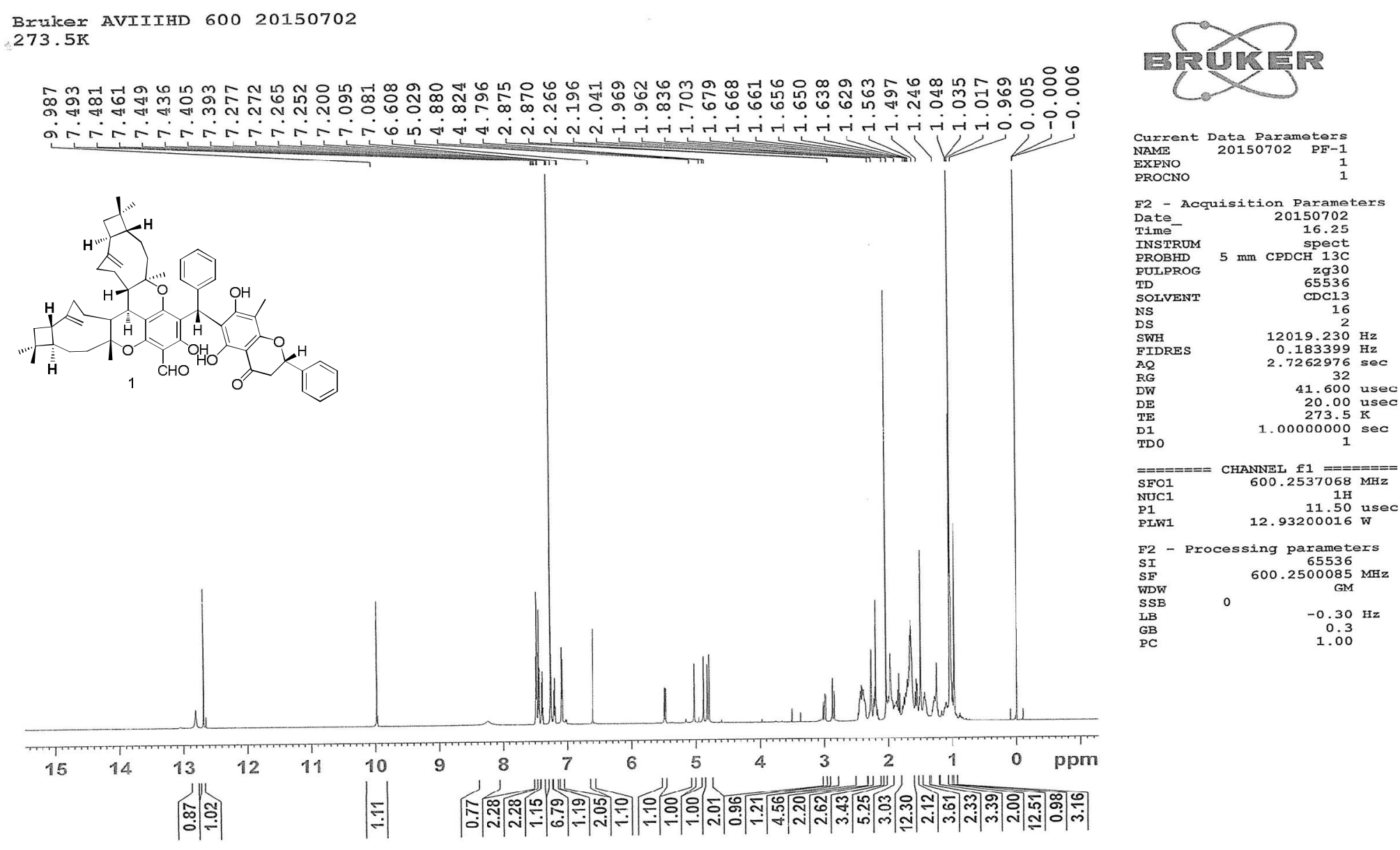


Figure S7. The ${ }^{1} \mathrm{H}$ NMR spectrum of guajavadimer A (1) in $\mathrm{CDCl}_{3}(600 \mathrm{MHz})$.

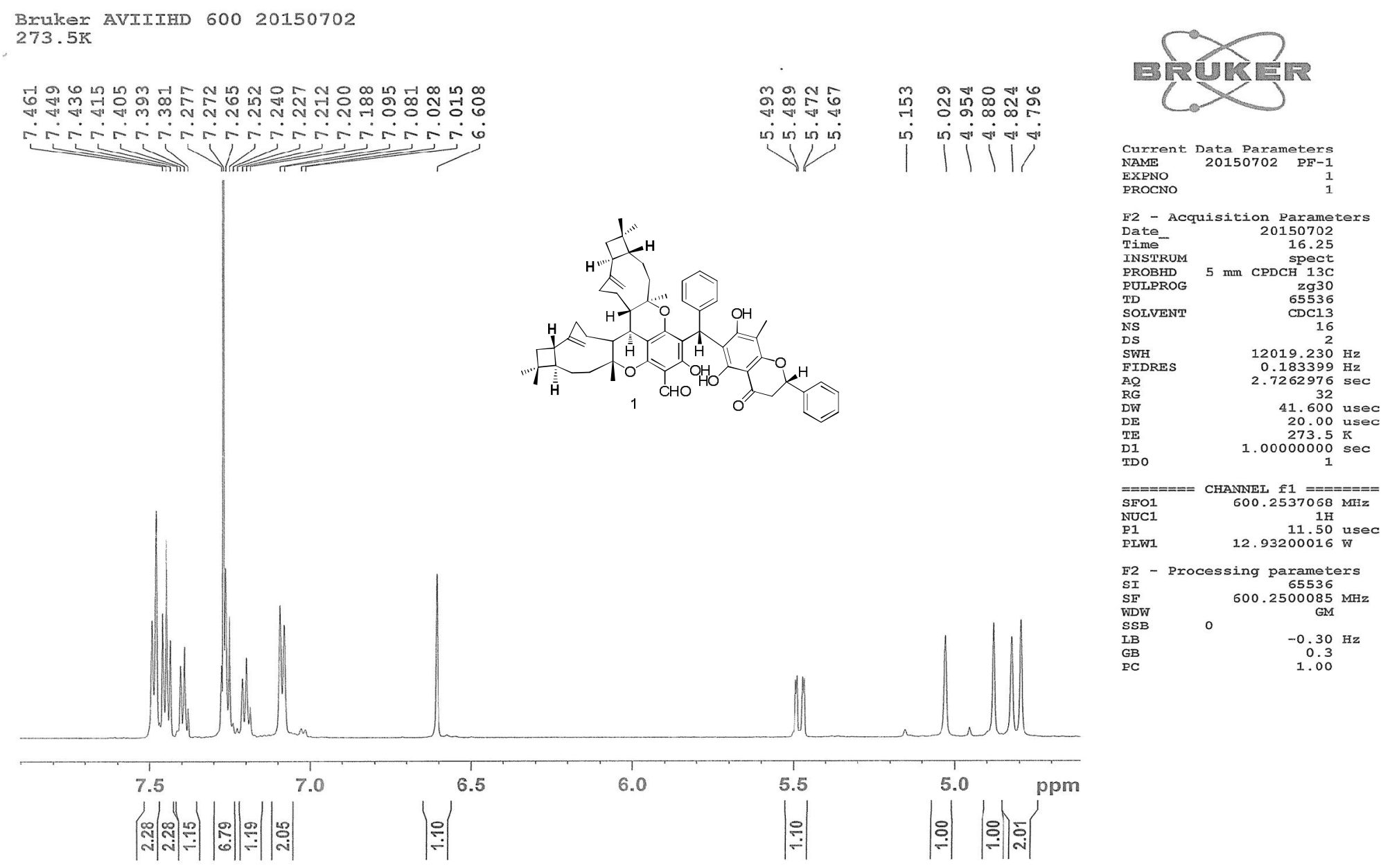


Figure S8. The ${ }^{1} \mathrm{H}$ NMR spectrum of guajavadimer A (1) in $\mathrm{CDCl}_{3}(600 \mathrm{MHz})$.

Bruker AVIIIHD 60020150702

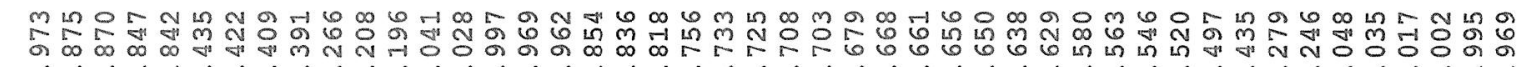

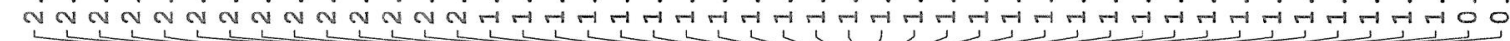
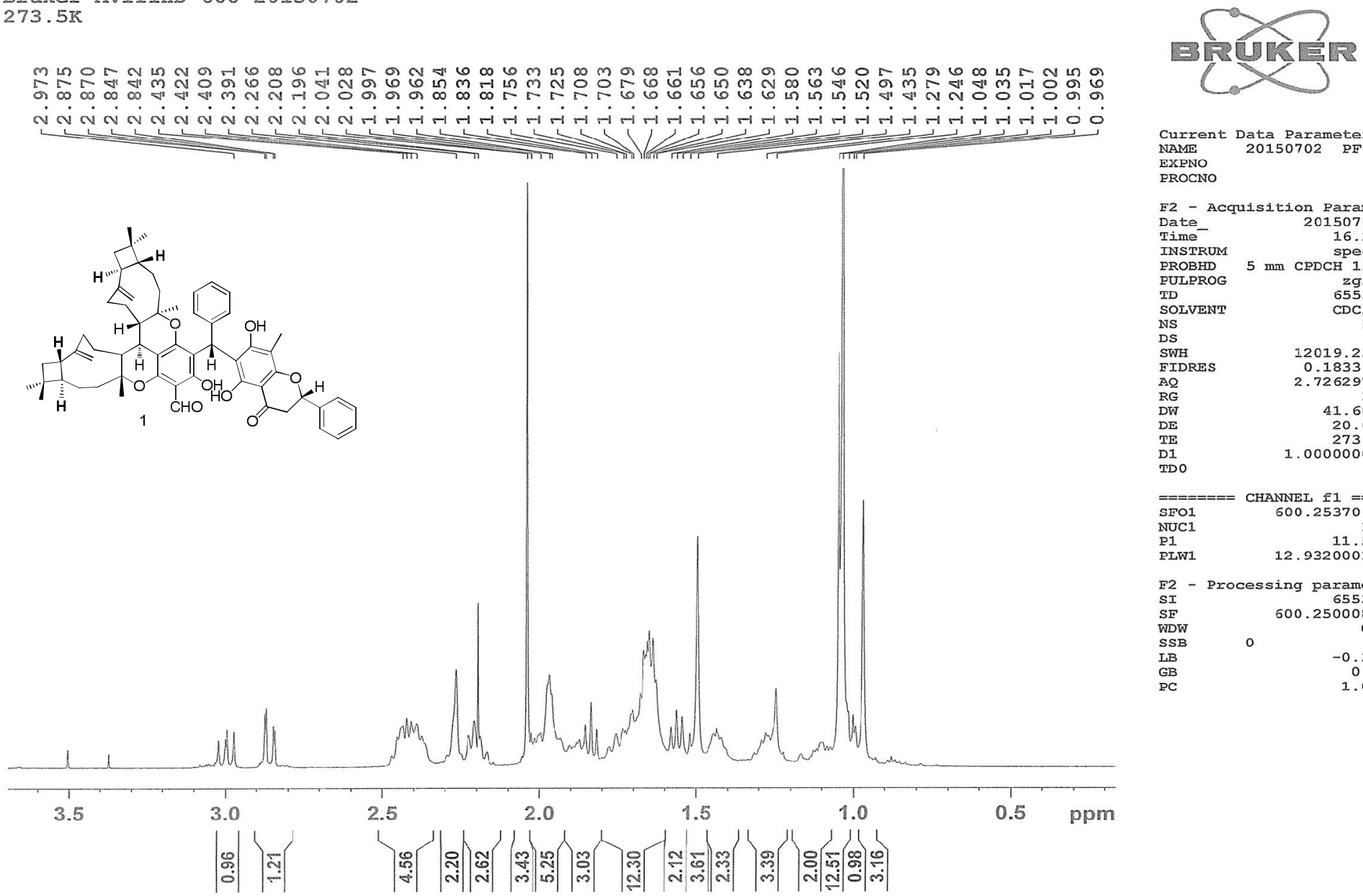

Current Data Parameters

$\begin{array}{lrr}\text { NAME } & 20150702 & \text { PF-1 } \\ \text { EXPNO } & 1 \\ \text { PROCNO } & 1\end{array}$

F2 - Acquisition Parameters

INSTRUM $\begin{aligned} 16.25 \\ \text { Spect }\end{aligned}$

PROBHD
PUIPROG $\mathrm{mm}$ CPDCH $13 \mathrm{C}$
$\mathrm{zg} 30$

SDOLVENT

DS

$\begin{array}{lrl}\text { SWH } & 12019.230 \mathrm{~Hz} \\ \text { STDPES } & 0.183399 \mathrm{~Hz}\end{array}$

AO 2.7262976 配

$\begin{array}{lr}R E & 31 \\ D W & 20.600 \text { usec } \\ D E & 273.5 \mathrm{~K} \mathrm{sec} \\ \mathrm{TE} & \end{array}$

TE

$1.00000000 \mathrm{sec}$

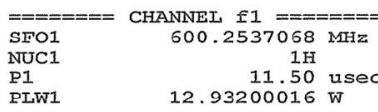

NUC
PLW

F2 - Processing parameters

$\begin{array}{ll}\text { SI } & 600.2500085 \\ \text { WDW } & \text { MHz }\end{array}$

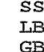

$-0.30 \mathrm{~Hz}$
0.3
1.00 
Figure S9 The ${ }^{13} \mathrm{C}$ NMR spectrum of guajavadimer A (1) in $\mathrm{CDCl}_{3}(150 \mathrm{MHz})$.

POR Bruker AVIIIHD 60020150120

BSULE 273.5

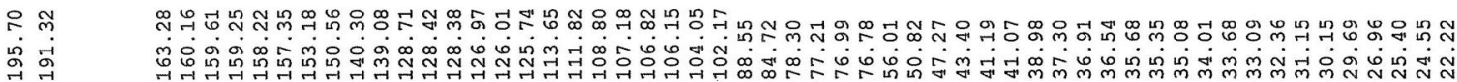

|
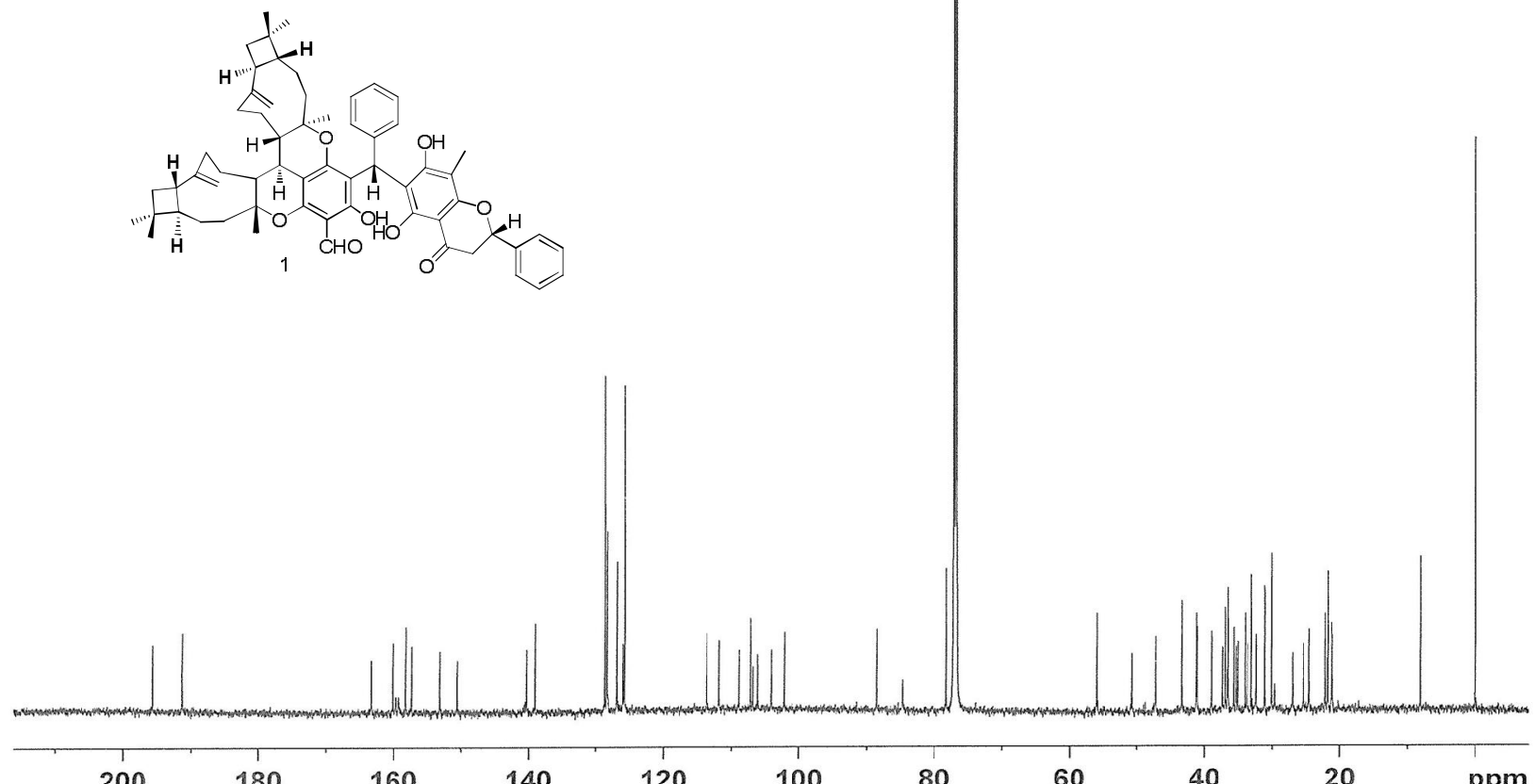

200

Current Data Parameters
NAME 20150702 PF-1

EXPNO 2

F2 - Acquisition Parameters

Time- $\quad 16.26$

INSTRUM 16 spect

PULPROG 5 zgpg30

$\begin{array}{ll}\text { TD } & 65536 \\ \text { SOLVENT } & \text { CDCl3 }\end{array}$

NS

400
4
$6057.691 \mathrm{~Hz}$

FIDRES $0.550197 \mathrm{H}$

$\begin{array}{lc}\mathrm{AQ} & 0.9087659 \mathrm{sec} \\ \mathrm{RG} & 2050 \\ \mathrm{DW} & 1356 \mathrm{sec}\end{array}$

$\begin{array}{ll}\text { DW } & 13.867 \text { usec } \\ \text { DE } & 31.37 \text { usec } \\ \text { TE } & 273.5 \mathrm{~K}\end{array}$

$\begin{array}{ll}\text { D1 } & \mathbf{1 . 0 0 0 0 0 0 0 0 ~ s e c} \\ \text { D11 } & 0.0300000 \mathrm{sec}\end{array}$

$\begin{array}{ll}\text { DD1 } & \mathbf{0 . 0 3 0 0 0 0 0} \\ \text { TD0 }\end{array}$

$=\underset{\text { CHANNEL } \mathrm{f} 1=}{\mathrm{SFO1}}=$

$\begin{array}{ll}\text { P1 } & 12.54 \text { usec } \\ \text { PLW1 } & 19.39800072 \mathrm{~W}\end{array}$

SFO2
NUC2 600.2524010 $\mathrm{MHz}$

NUC2 $1 \mathrm{H}$

PCPD2 2 waltz16
80.00 usec

PLW2 12.93200016 W

PLW13 $0.17103000 \mathrm{w}$

F2 - Processing parameters

SF $\quad \begin{array}{ll}32.9368 \\ \text { SI }\end{array}$

${ }_{S S B}{ }_{0} \quad$ EM

LB $\quad 2.00 \mathrm{~Hz}$

PC

1.40 
Figure S10 The ${ }^{13} \mathrm{C}$ NMR spectrum of guajavadimer $\mathrm{A}(\mathbf{1})$ in $\mathrm{CDCl}_{3}(150 \mathrm{MHz})$.

Bruker AVIIIHD 60020150120

$=C M E R \quad 273.5 \mathrm{~K}$

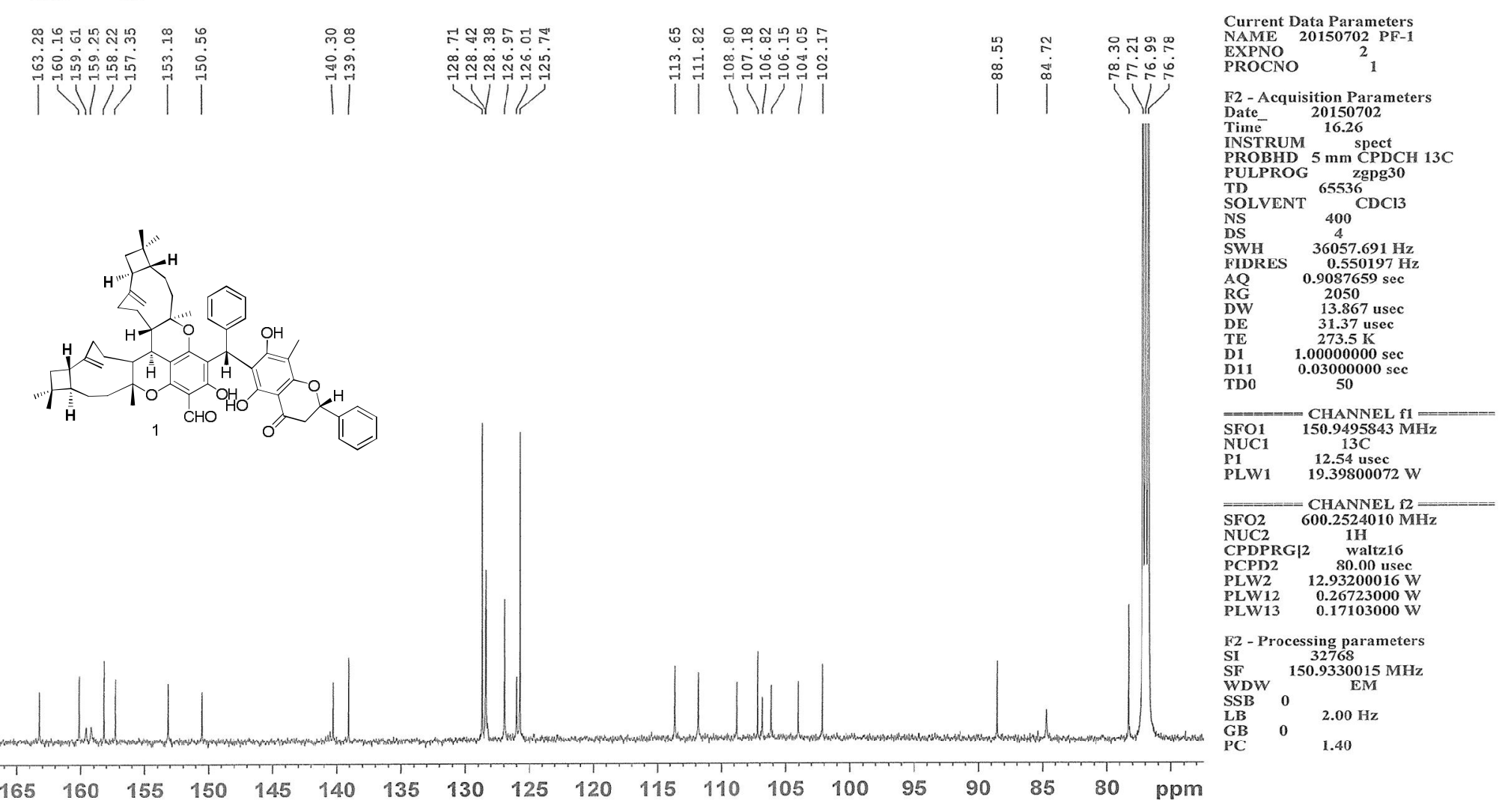


Figure S11 The ${ }^{13} \mathrm{C}$ NMR spectrum of guajavadimer $\mathrm{A}(\mathbf{1})$ in $\mathrm{CDCl}_{3}(150 \mathrm{MHz})$.

= DURE Bruker AVIIIHD 60020150120

EIU⿴囗十) $273.5 \mathrm{~K}$
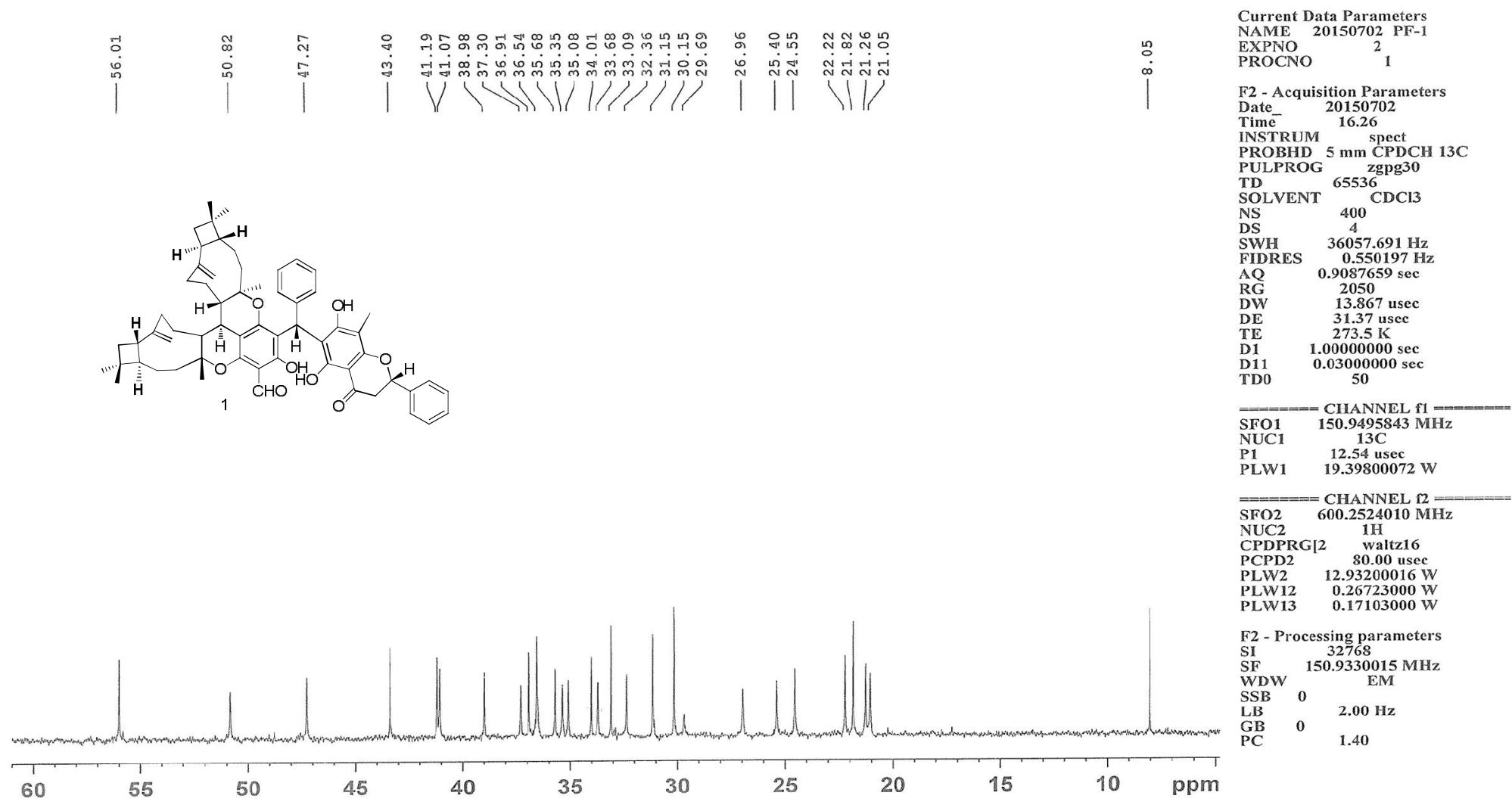
Figure S12. The DEPT spectrum of guajavadimer A (1) in $\mathrm{CDCl}_{3}(150 \mathrm{MHz})$.

Bruker AVIIIHD 60020150120 DEPT PF-1

BTURER $273.5 \mathrm{~K}$
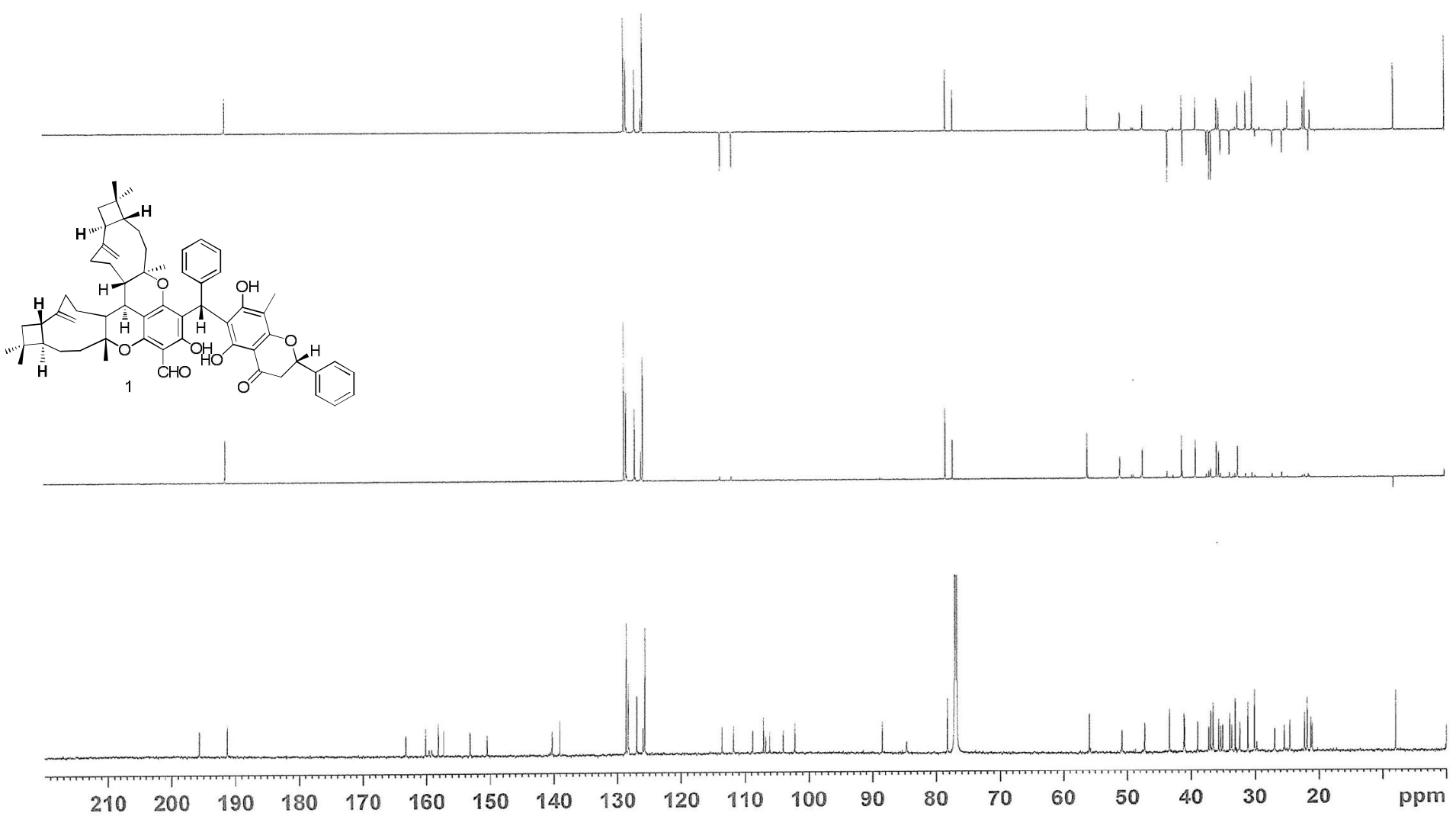
Figure S13. The DEPT spectrum of guajavadimer A (1) in $\mathrm{CDCl}_{3}(150 \mathrm{MHz})$.

CP Bruker AVIIIHD 60020150120 DEPT PF-1

BRUKRER $273.5 \%$
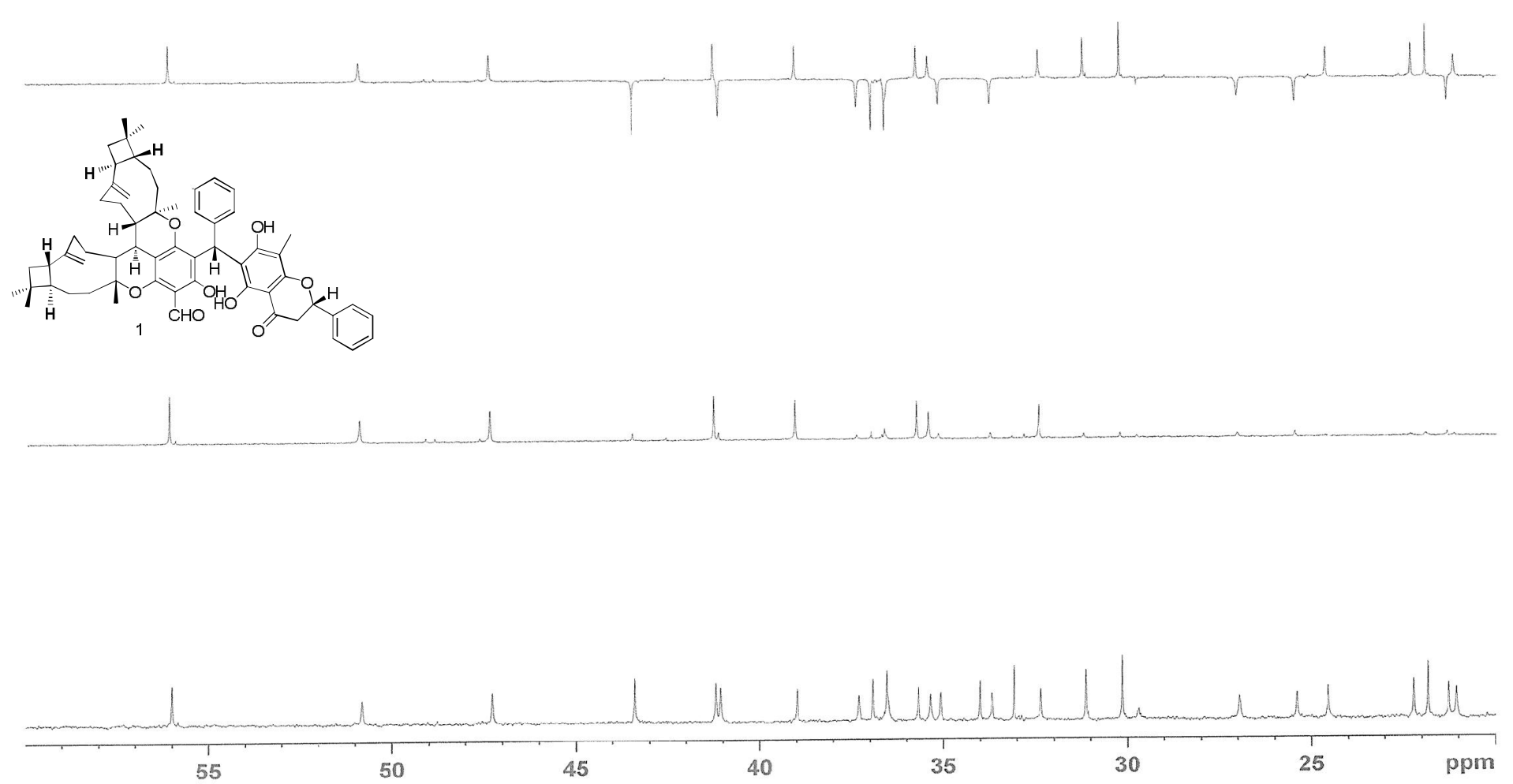
Figure S14. The DEPT spectrum of guajavadimer A (1) in $\mathrm{CDCl}_{3}(150 \mathrm{MHz})$.

PDP Bruker AVIIIHD 60020150120 DEPT PE-1

$(S<) 273.5 \mathrm{~K}$
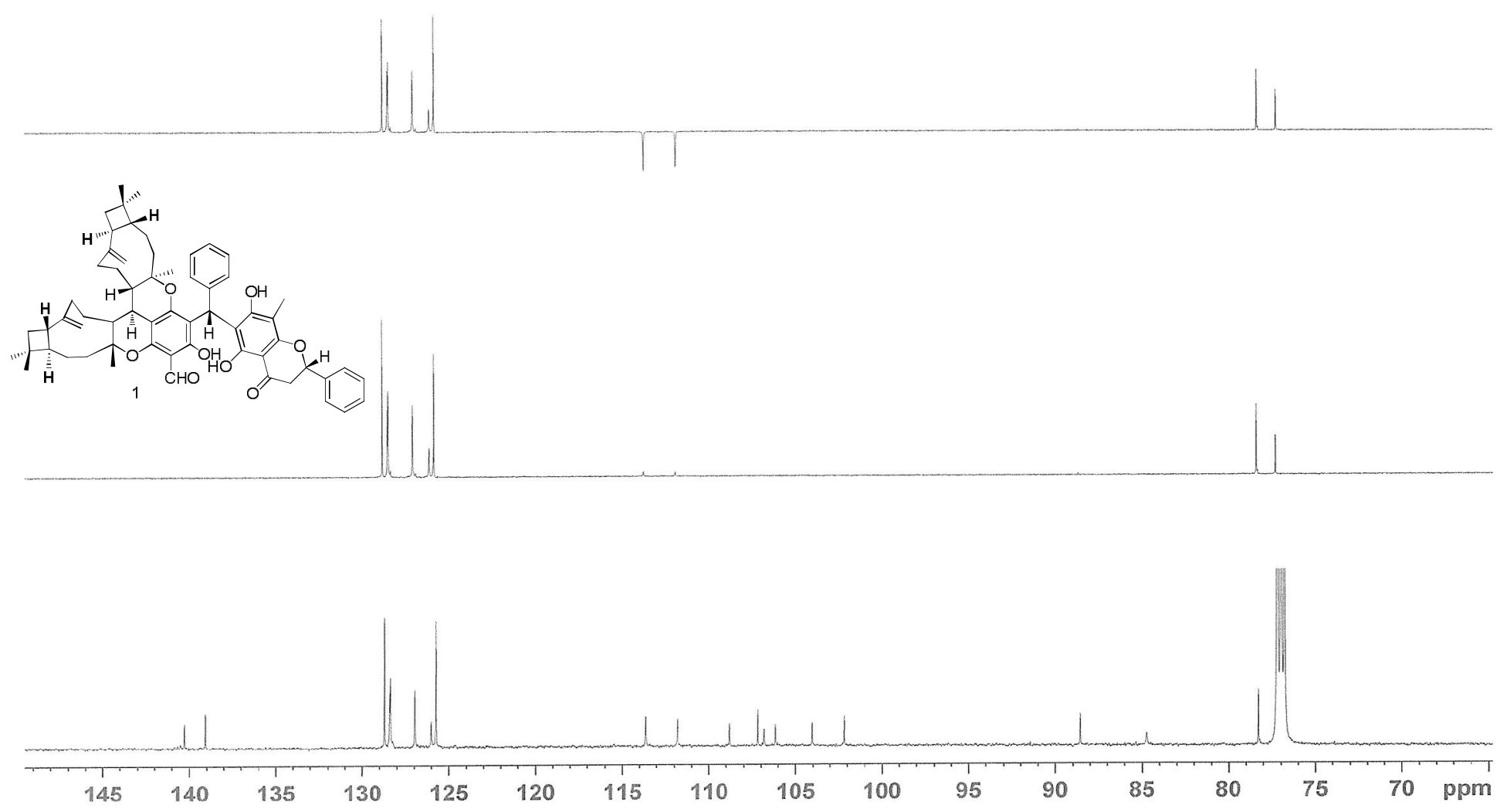
Figure $\mathrm{S} 15$ The ${ }^{1} \mathrm{H}-{ }^{1} \mathrm{H}$ COSY spectrum of guajavadimer $\mathrm{A}(\mathbf{1})$ in $\mathrm{CDCl}_{3}(600 \mathrm{MHz})$.

Bruker AVIIIHD 60020150713

COSY MOF CDC13 D: \\ DATA2015 43
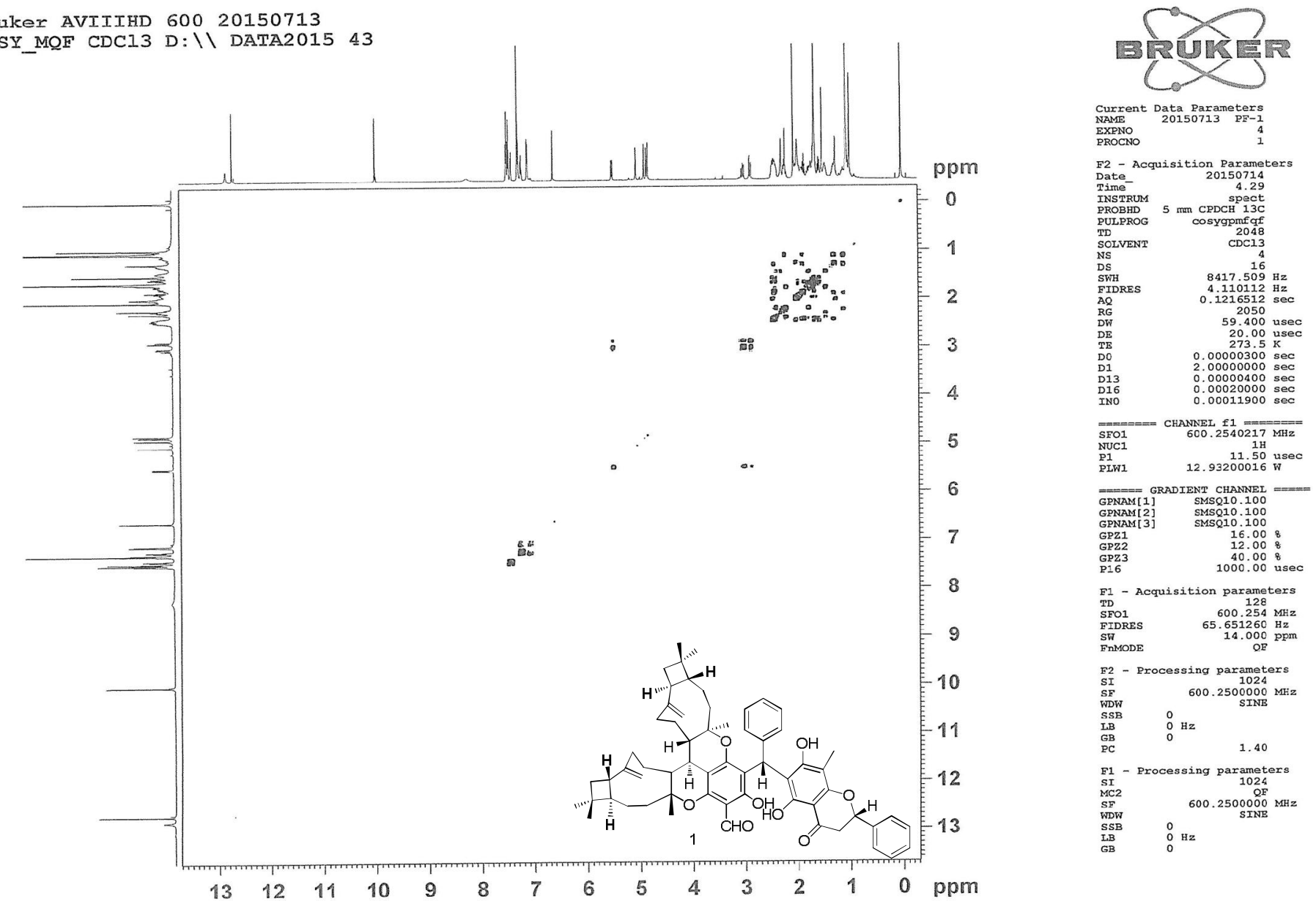
Figure S16. The ${ }^{1} \mathrm{H}-{ }^{1} \mathrm{H}$ COSY spectrum of guajavadimer A (1) in $\mathrm{CDCl}_{3}(600 \mathrm{MHz})$.
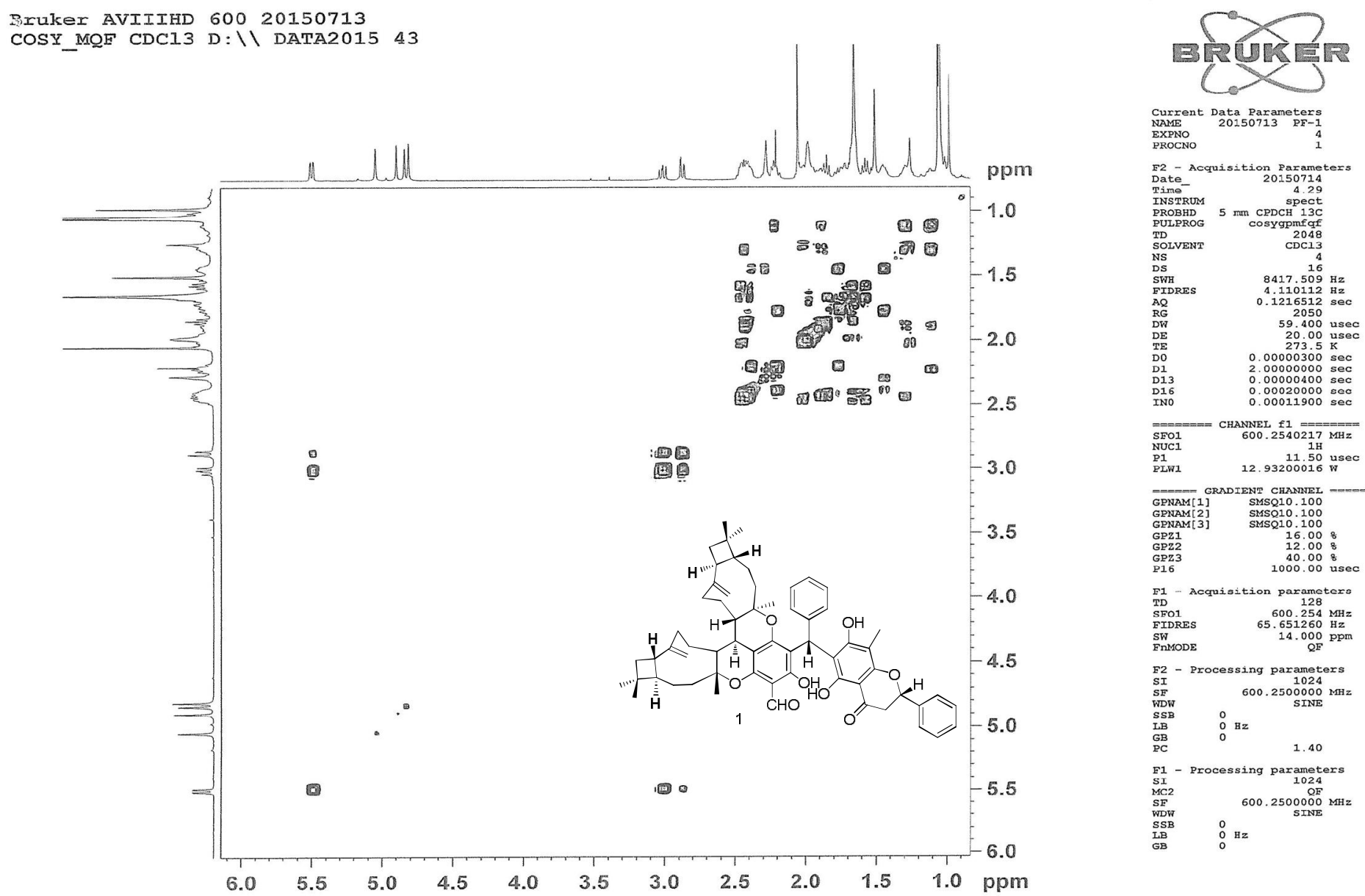
Figure S17. The ${ }^{1} \mathrm{H}^{1}{ }^{1} \mathrm{H}$ COSY spectrum of guajavadimer A (1) in $\mathrm{CDCl}_{3}(600 \mathrm{MHz})$.
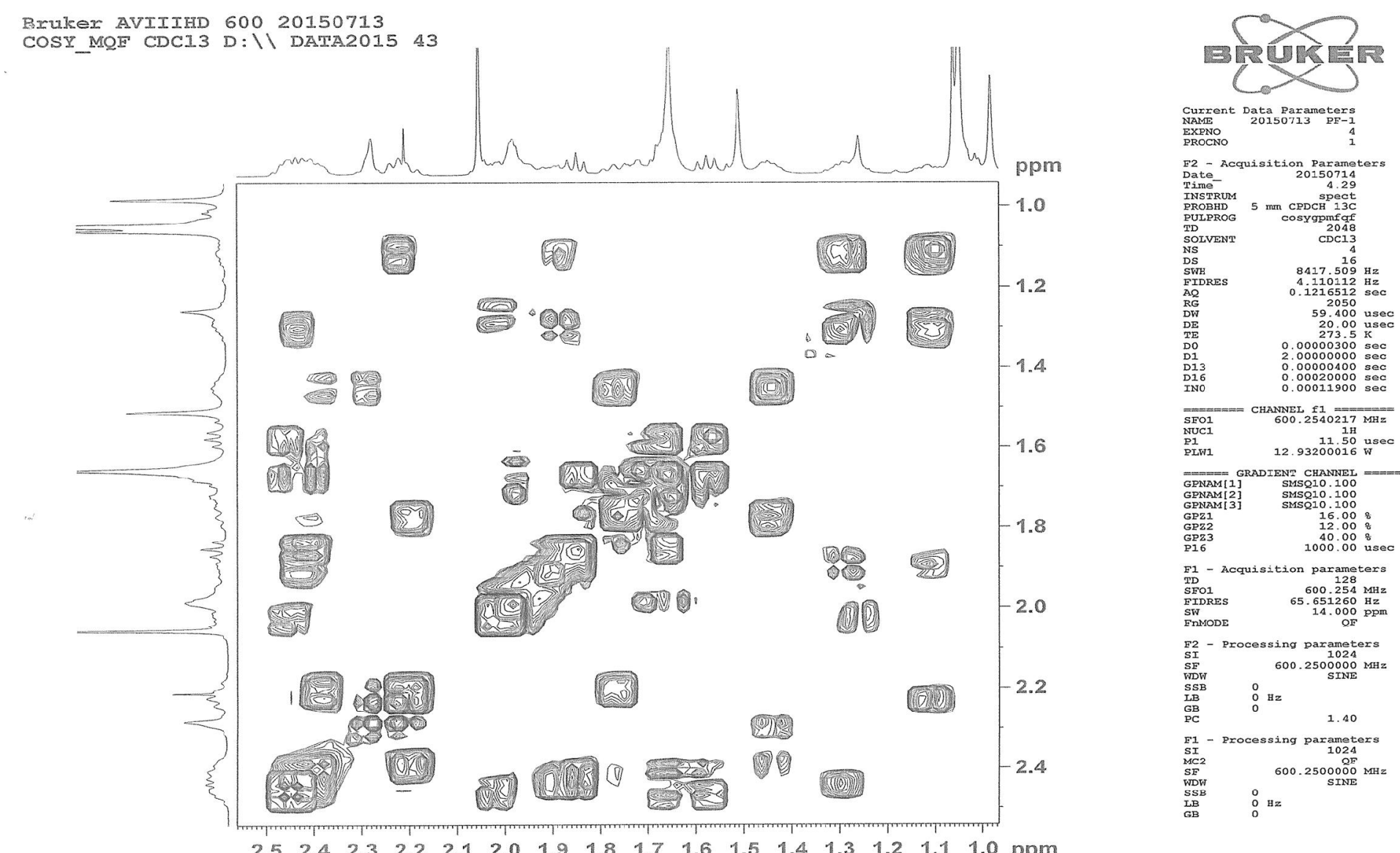
Figure S18. The HSQC spectrum of guajavadimer $\mathrm{A}(\mathbf{1})$ in $\mathrm{CDCl}_{3}(600 \mathrm{MHz})$.
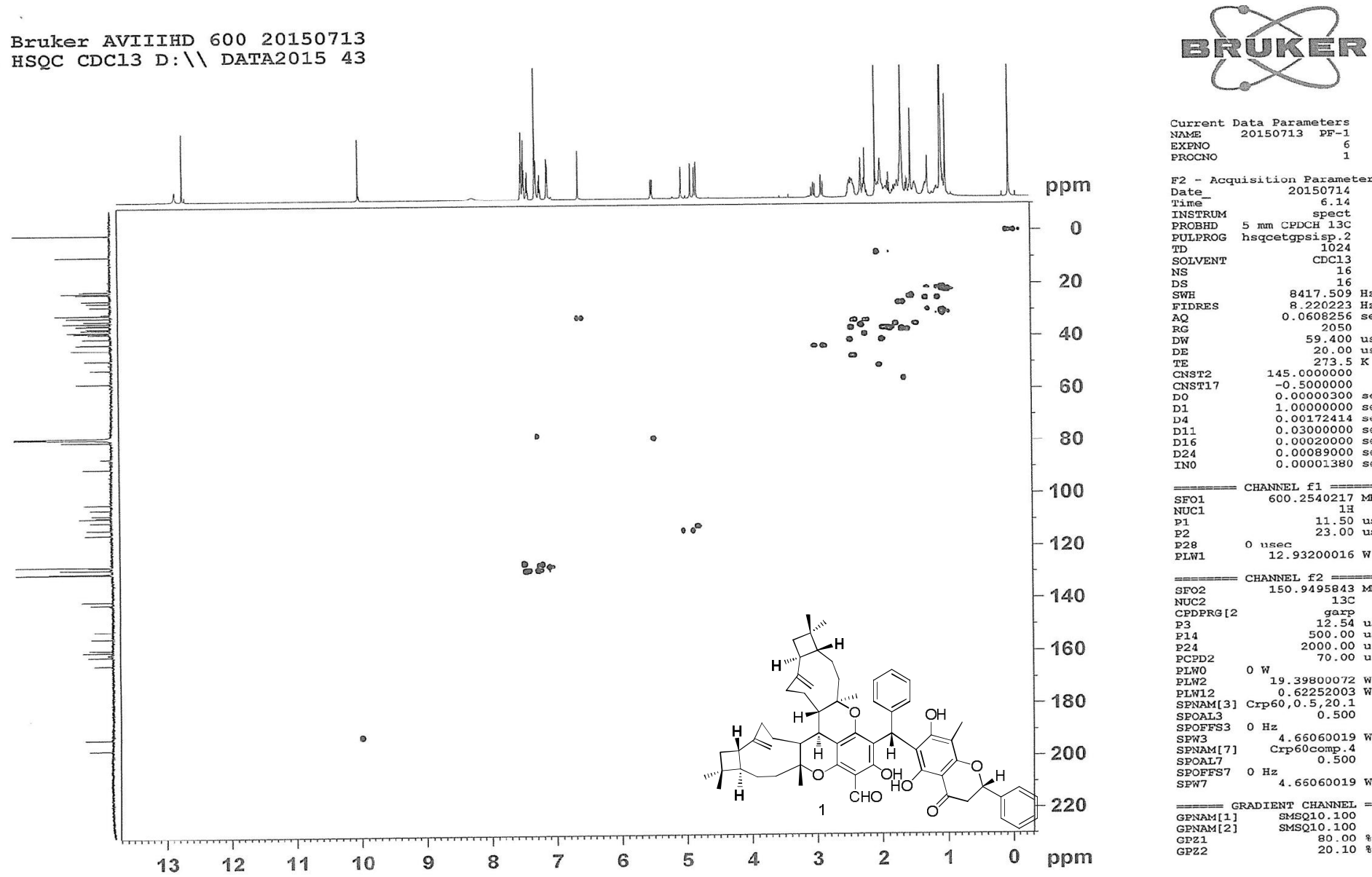

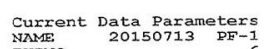

EXPNO
PRCONO

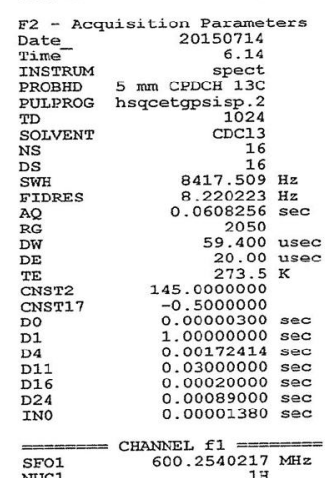

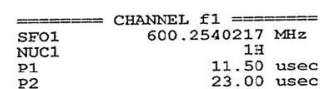

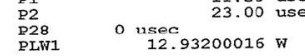

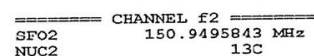

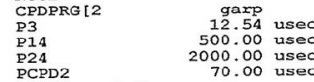

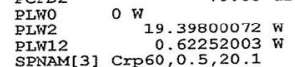

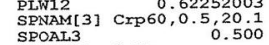

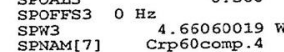

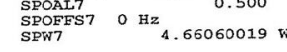

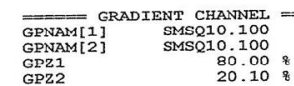


Figure S19. The HSQC spectrum of guajavadimer A (1) in $\mathrm{CDCl}_{3}(600 \mathrm{MHz})$.

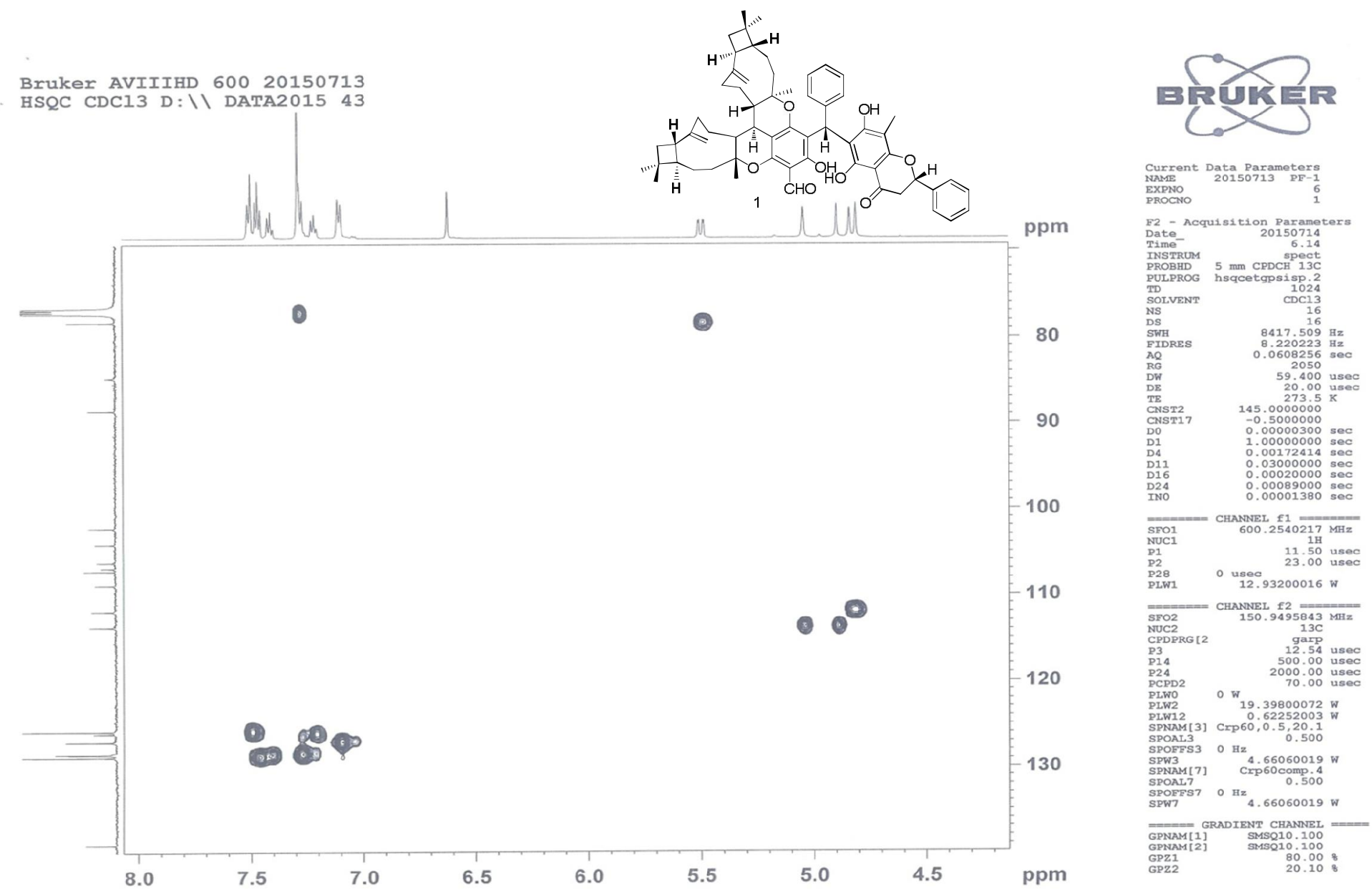


Figure S20. The HSQC spectrum of guajavadimer A (1) in $\mathrm{CDCl}_{3}(600 \mathrm{MHz})$.
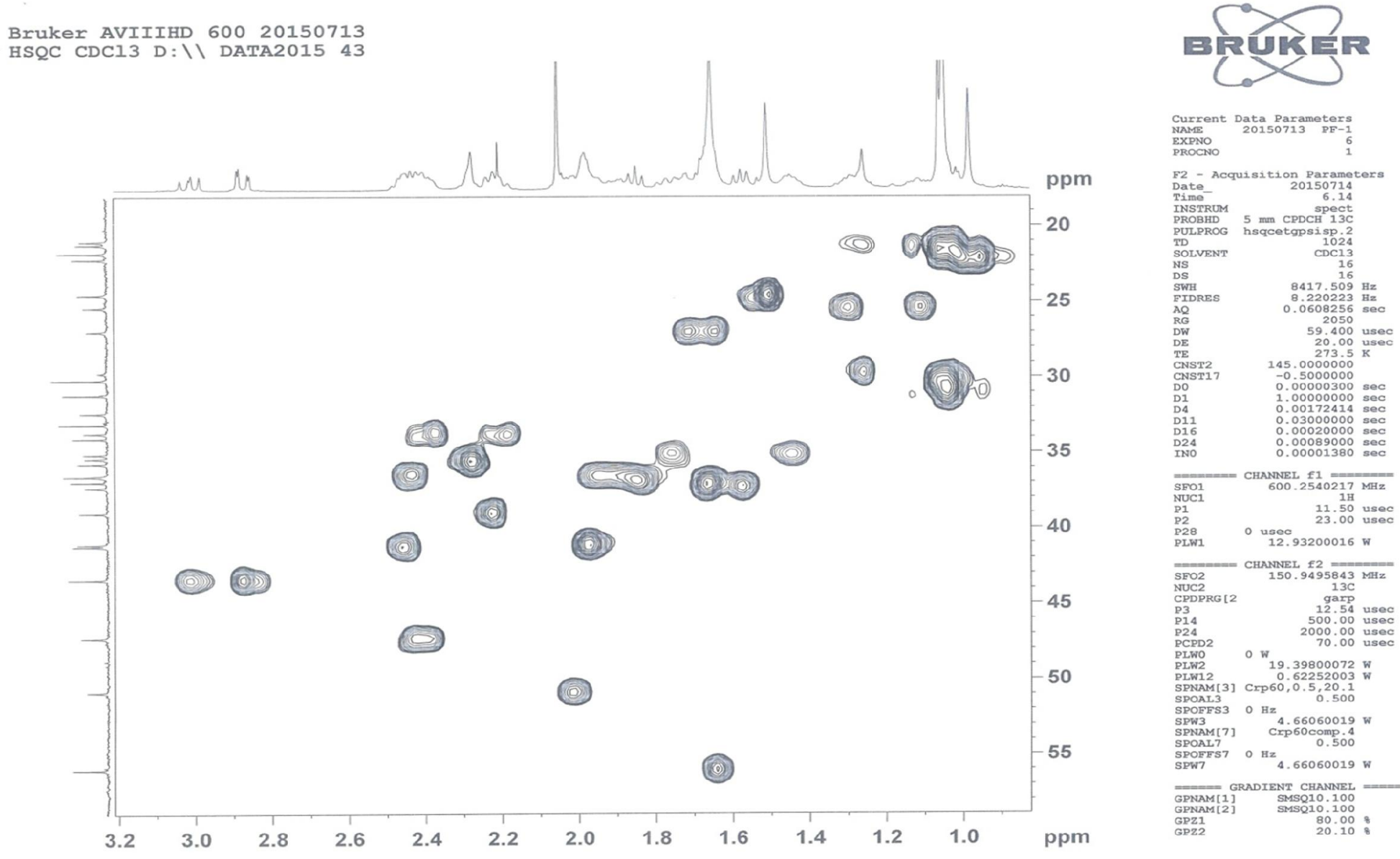
Figure S 21. The HMBC spectrum of guajavadimer $\mathrm{A}(\mathbf{1})$ in $\mathrm{CDCl}_{3}(600 \mathrm{MHz})$.

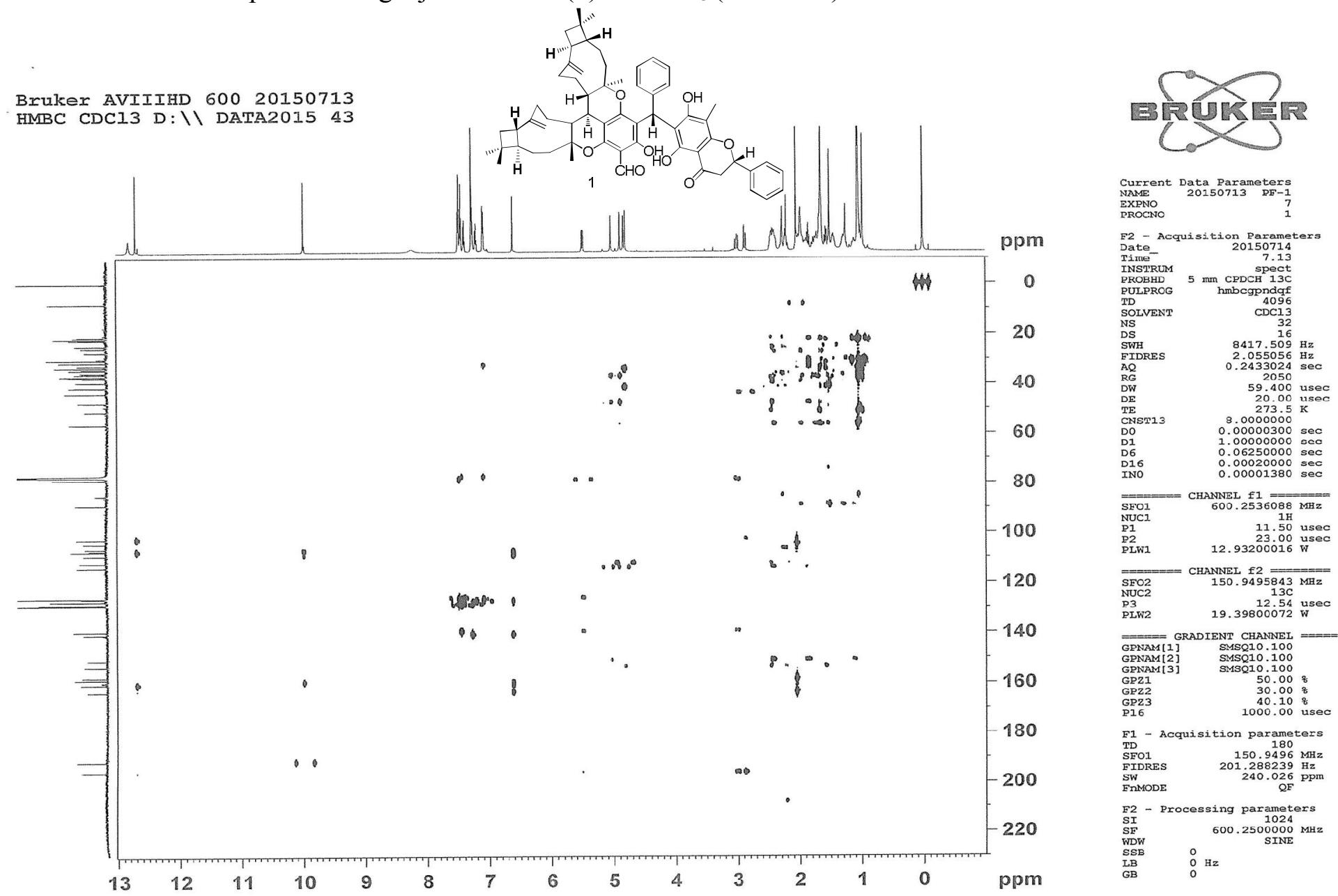


Figure S22. The HMBC spectrum of guajavadimer $\mathrm{A}(\mathbf{1})$ in $\mathrm{CDCl}_{3}(600 \mathrm{MHz})$.

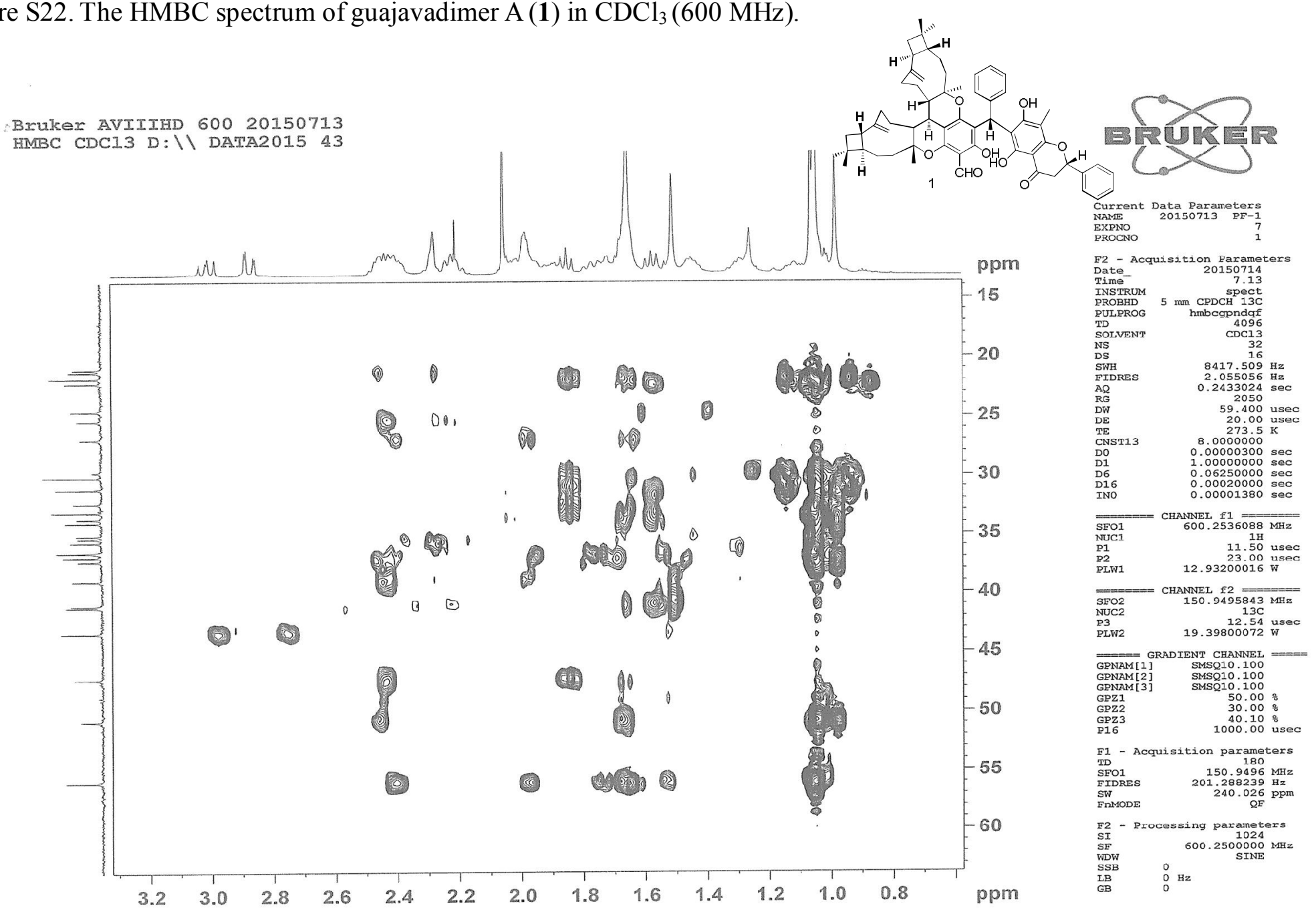


Figure S23. The HMBC spectrum of guajavadimer $\mathrm{A}(\mathbf{1})$ in $\mathrm{CDCl}_{3}(600 \mathrm{MHz})$.

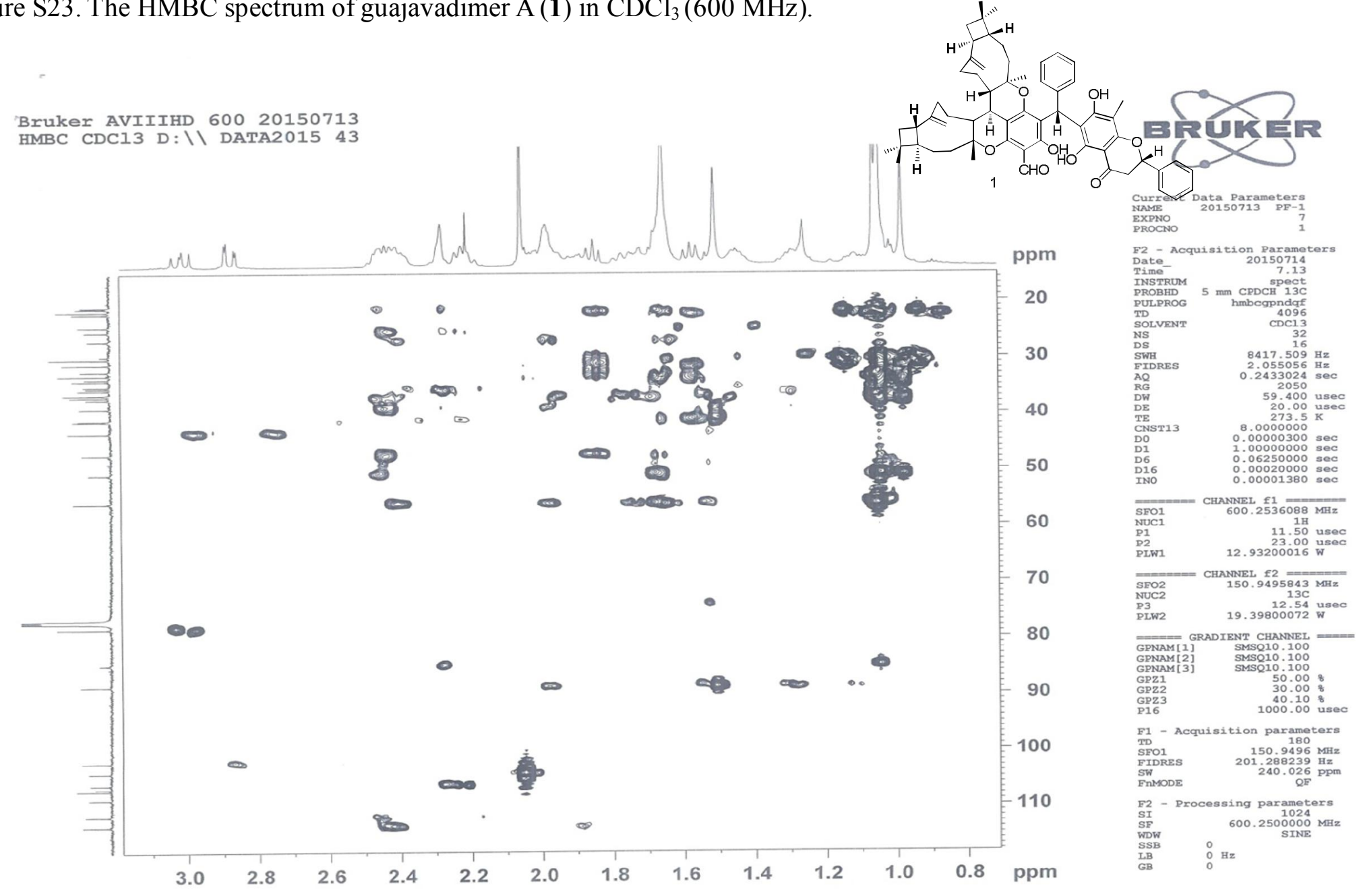


Figure S24. The HMBC spectrum of guajavadimer $\mathrm{A}(\mathbf{1})$ in $\mathrm{CDCl}_{3}(600 \mathrm{MHz})$.

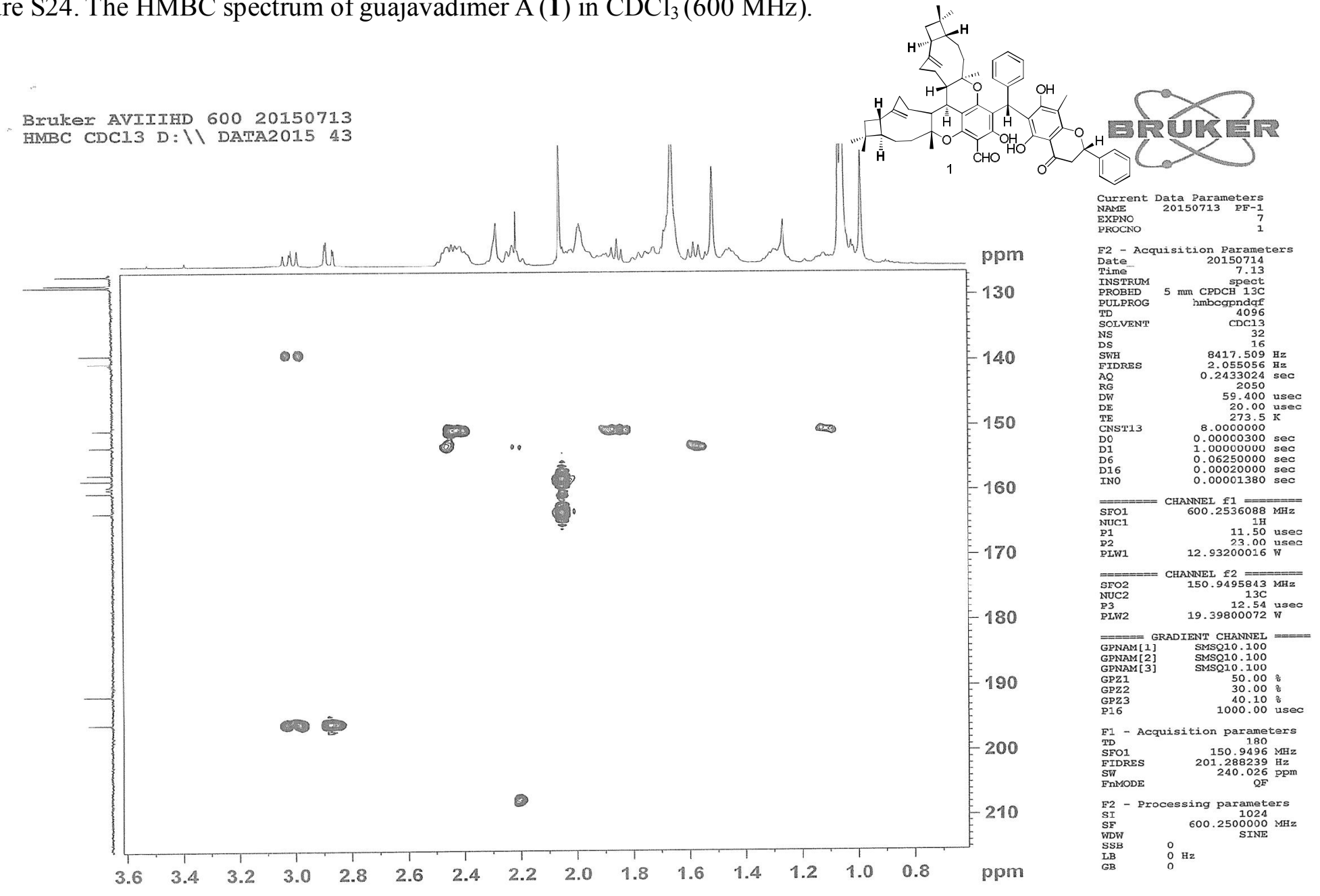


Figure S25. The HMBC spectrum of guajavadimer A(1) in $\mathrm{CDCl}_{3}(600 \mathrm{MHz})$.

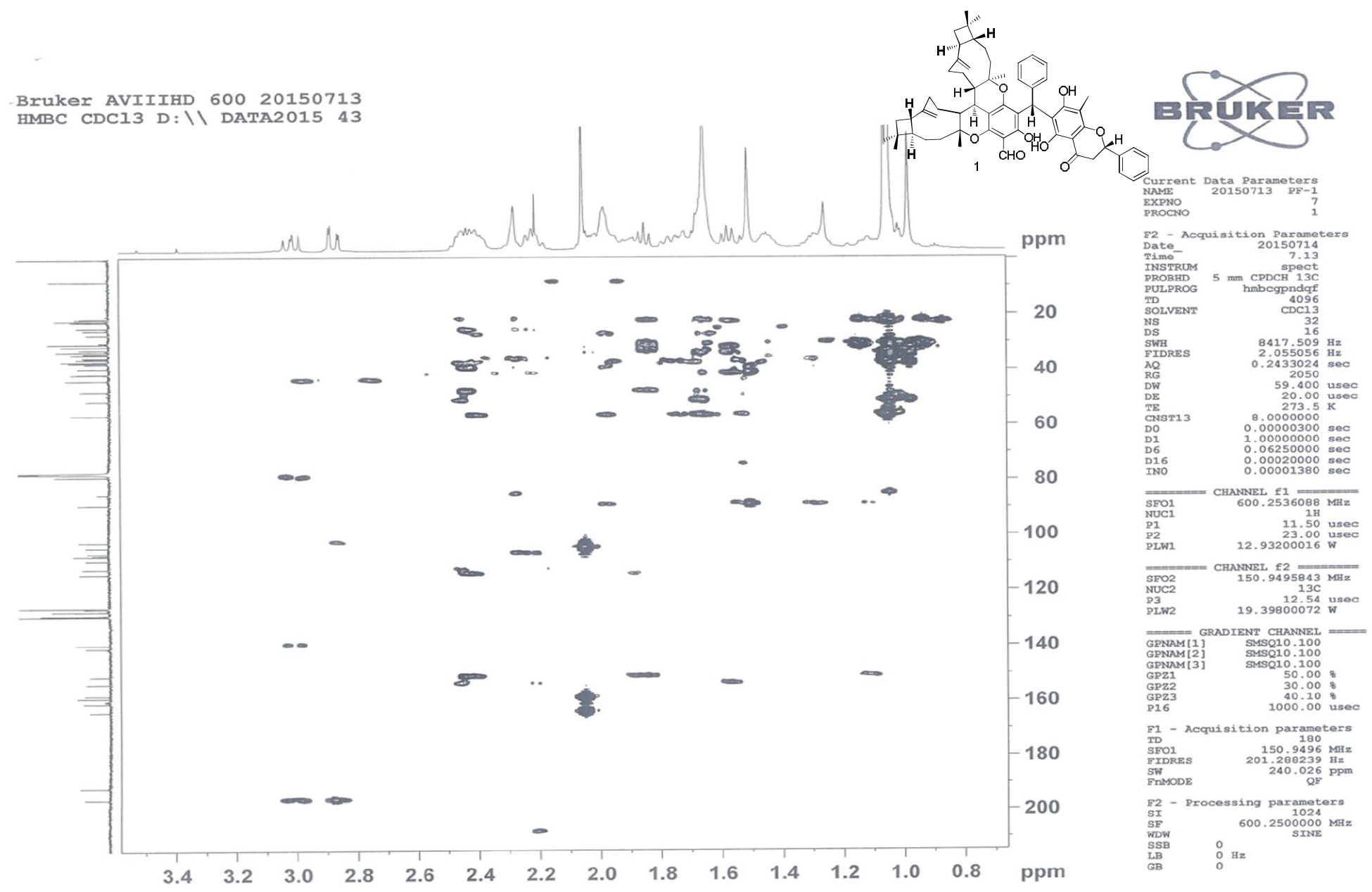


Figure S26. The HMBC spectrum of guajavadimer $\mathrm{A}(\mathbf{1})$ in $\mathrm{CDCl}_{3}(600 \mathrm{MHz})$.

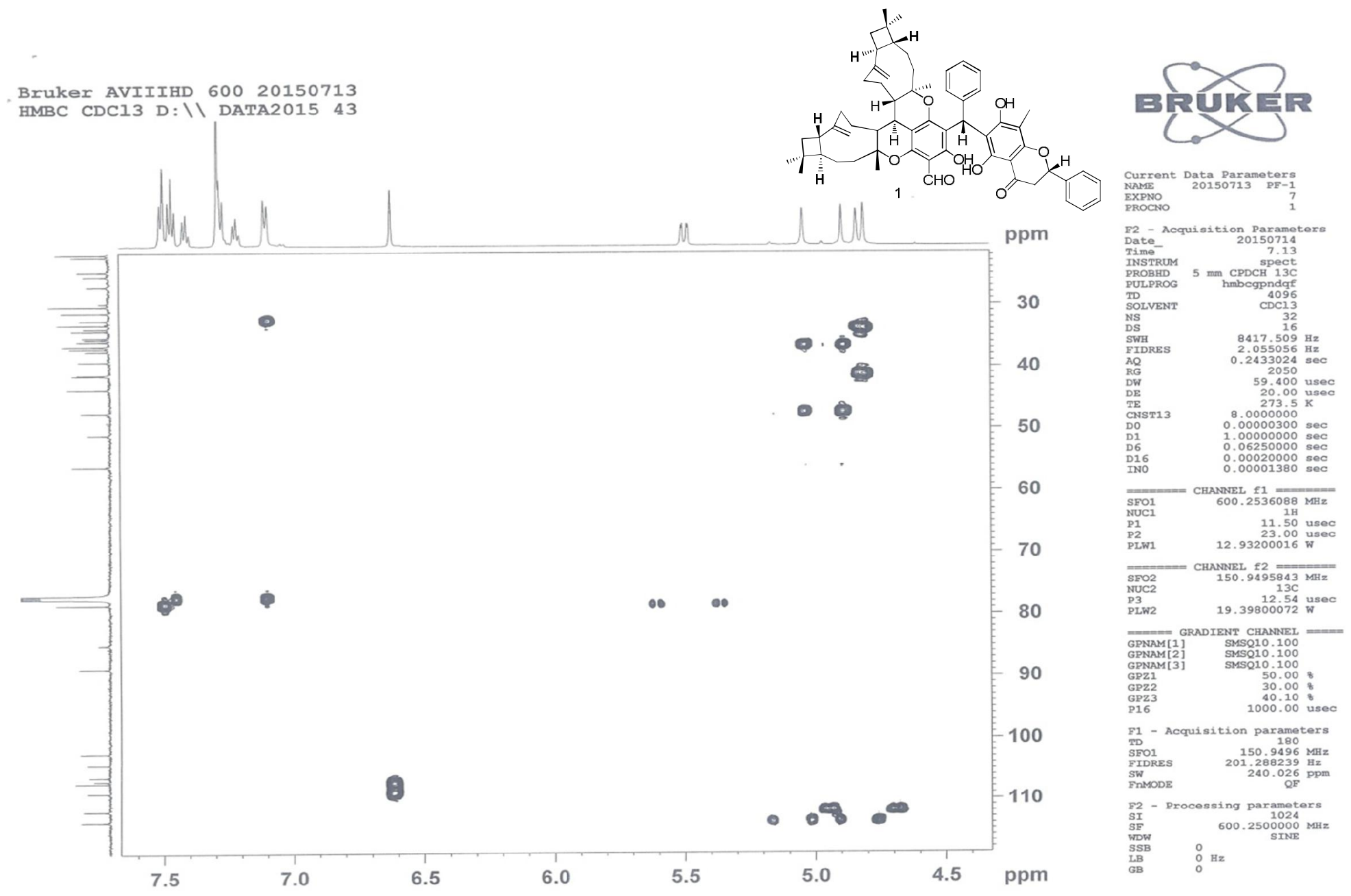


Figure S27. The HMBC spectrum of guajavadimer A (1) in $\mathrm{CDCl}_{3}(600 \mathrm{MHz})$.

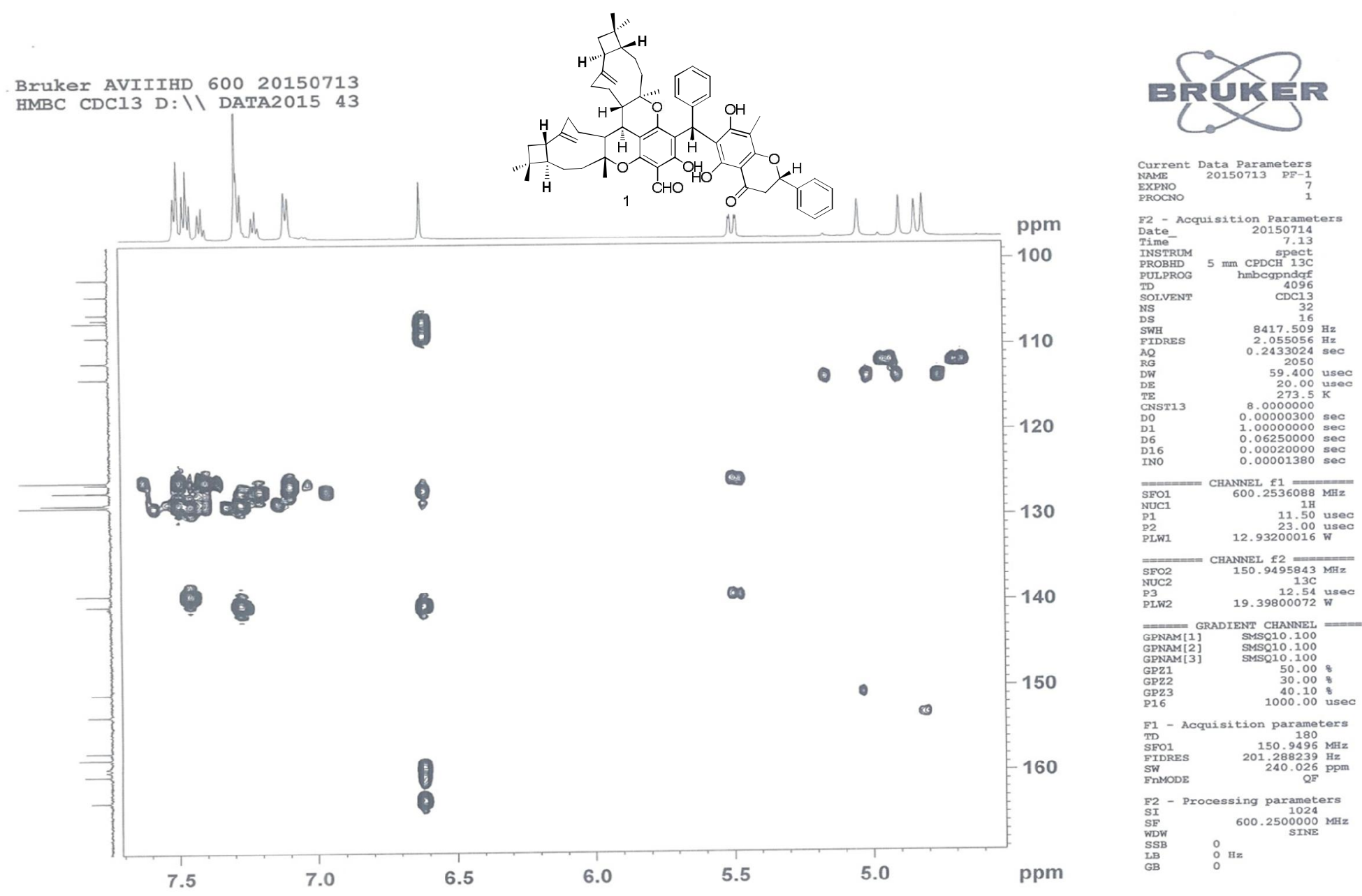


Figure S28. The HMBC spectrum of guajavadimer $\mathrm{A}(\mathbf{1})$ in $\mathrm{CDCl}_{3}(600 \mathrm{MHz})$.

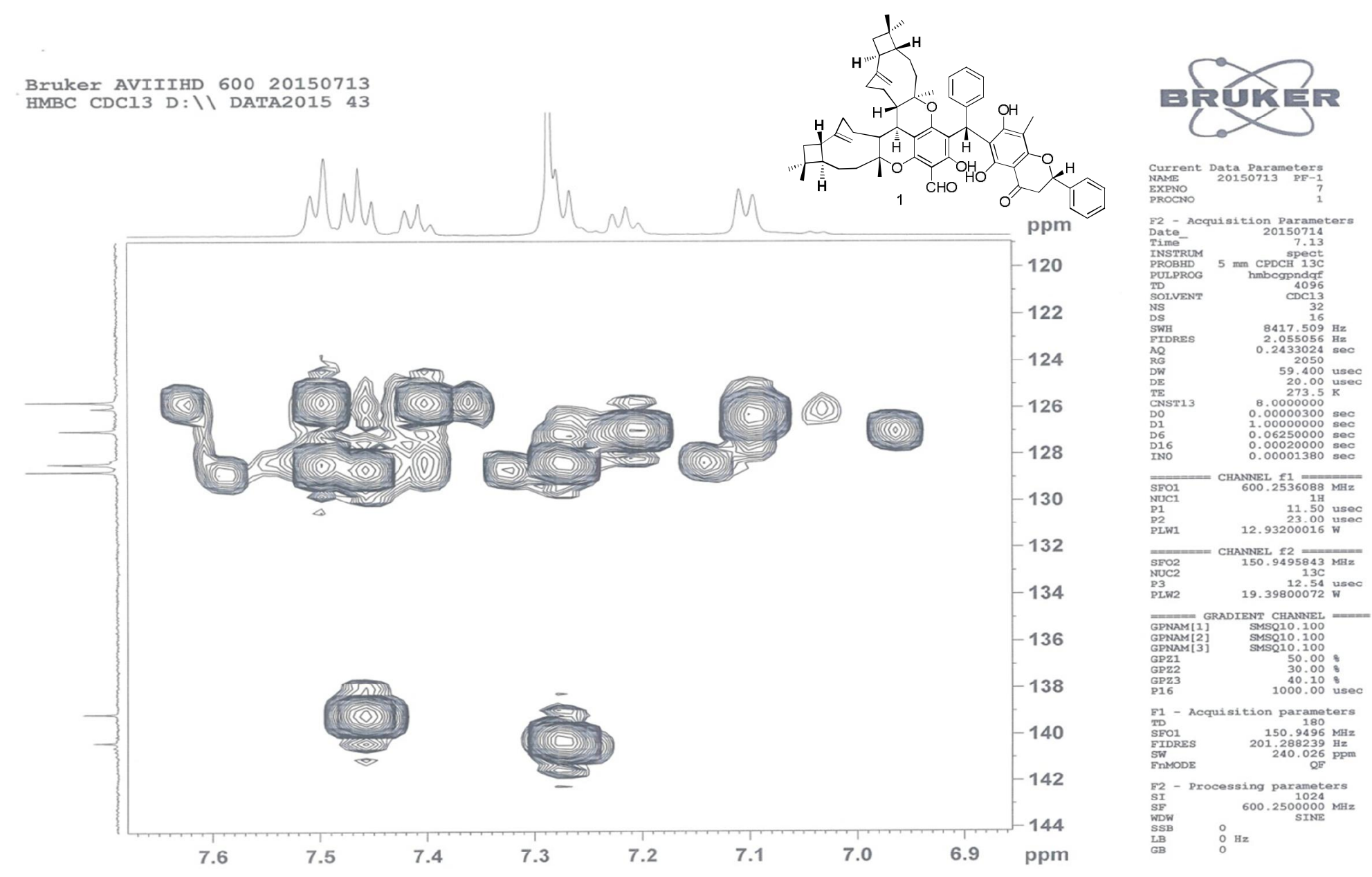


Figure S29. The NOESY spectrum of guajavadimer A (1) in $\mathrm{CDCl}_{3}(600 \mathrm{MHz})$.
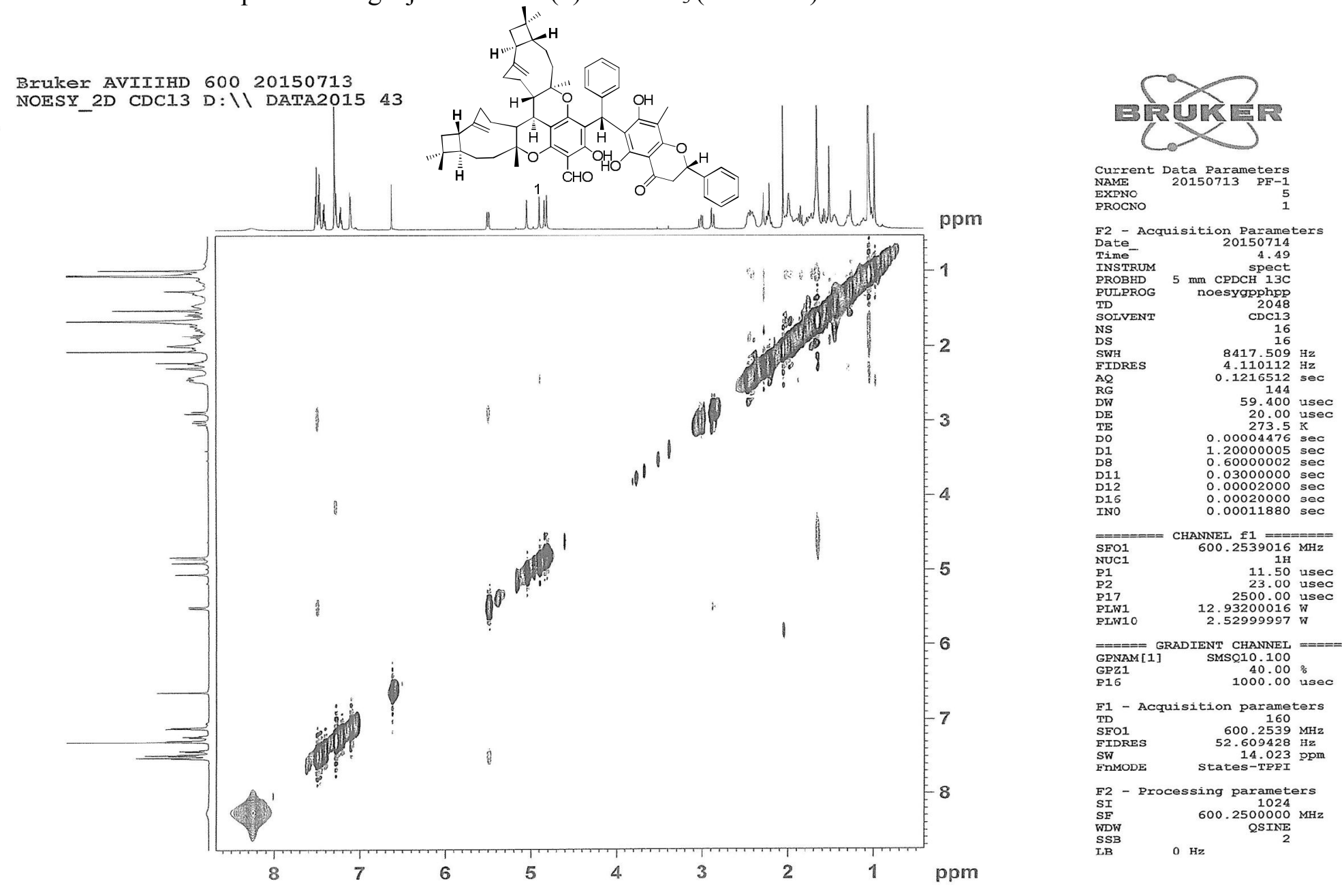
Figure S30. The NOESY spectrum of guajavadimer $\mathrm{A}(\mathbf{1})$ in $\mathrm{CDCl}_{3}(600 \mathrm{MHz})$.

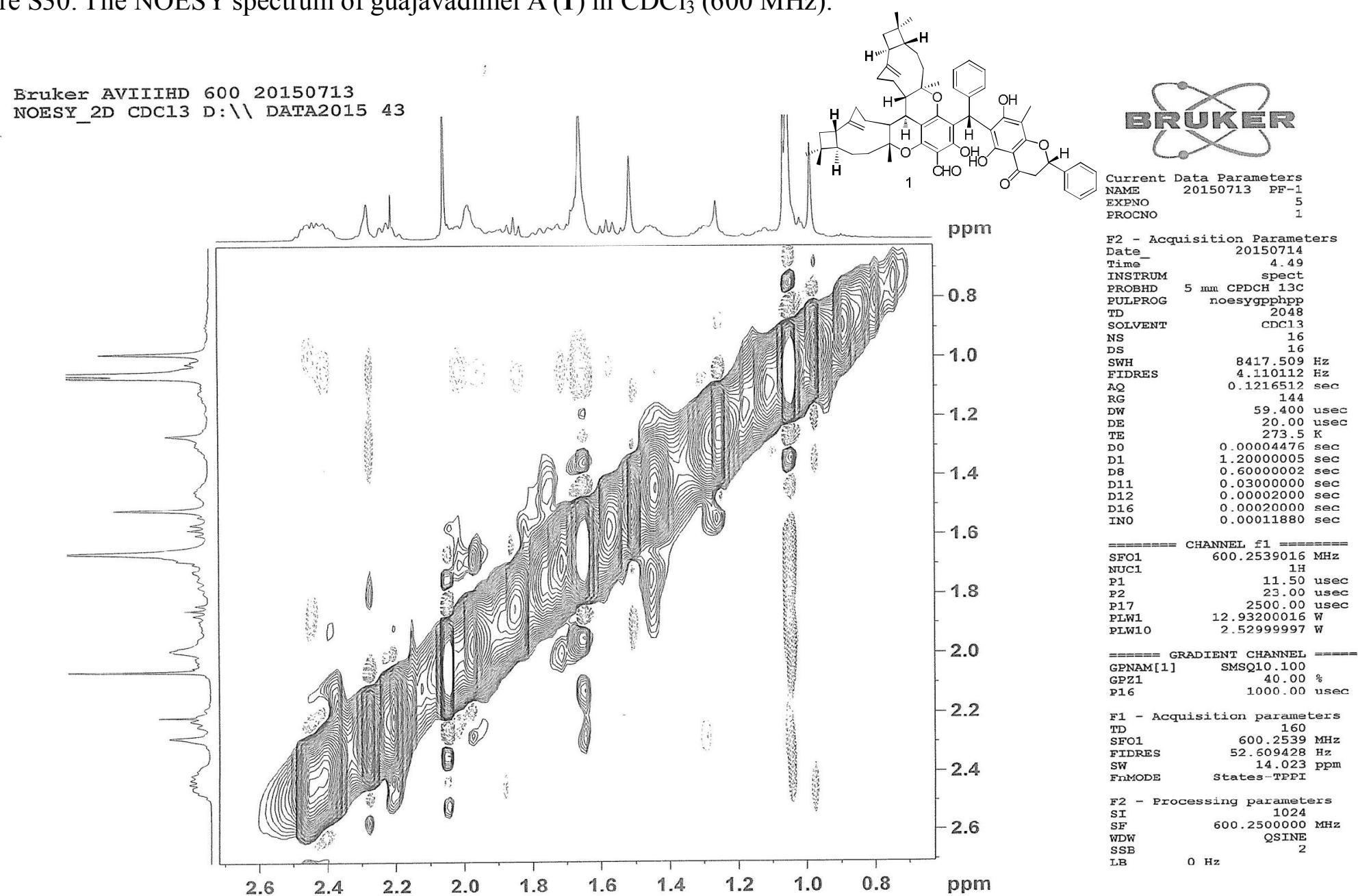


Figure S31. The TOCSY spectrum of guajavadimer A (1) in $\mathrm{CDCl}_{3}(600 \mathrm{MHz})$

Bruker AVIIIHD 60020150713

Bruker AVIIIHD 600 20150713
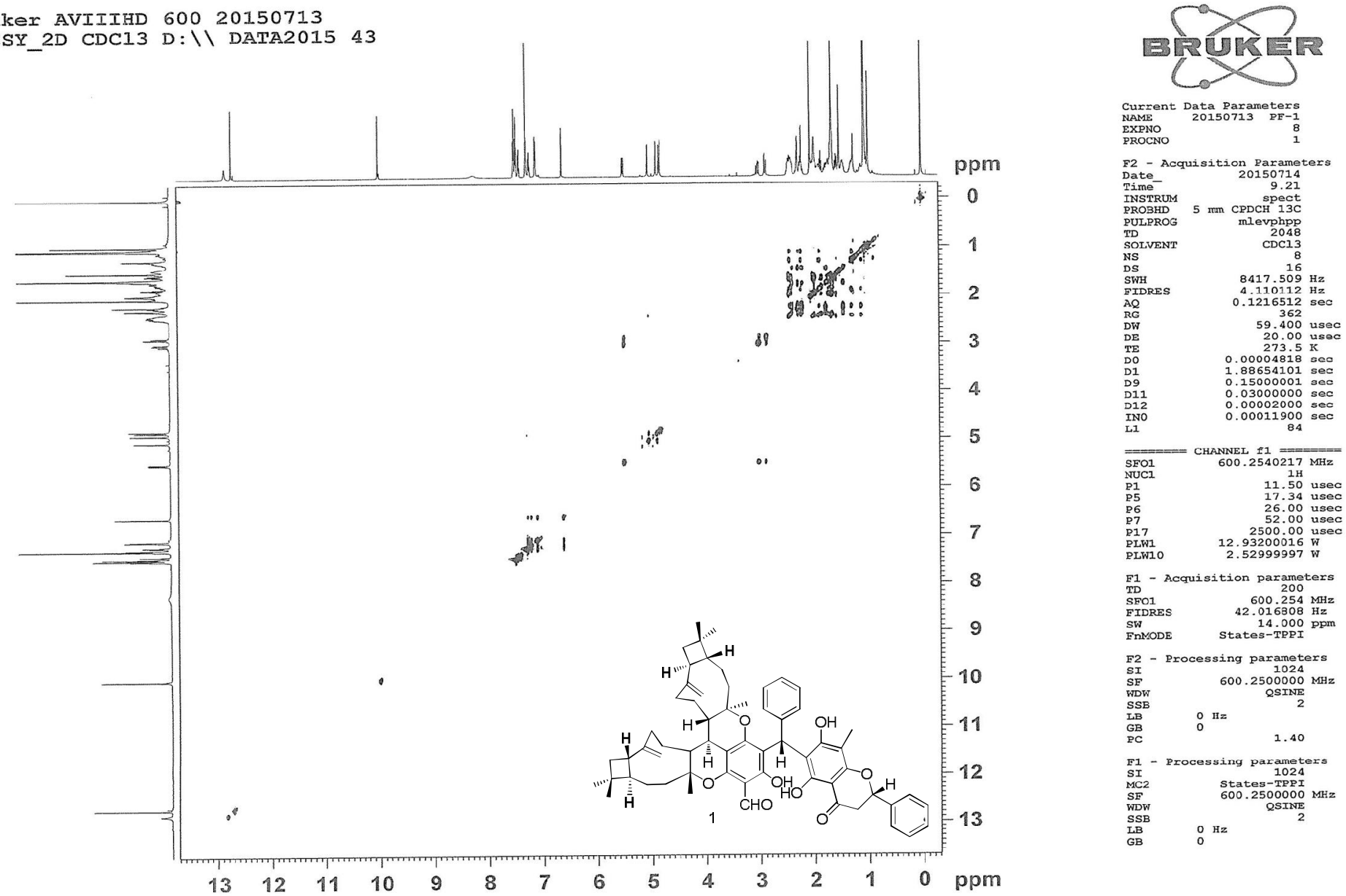
Figure S32. The TOCSY spectrum of guajavadimer A (1) in $\mathrm{CDCl}_{3}(600 \mathrm{MHz})$.
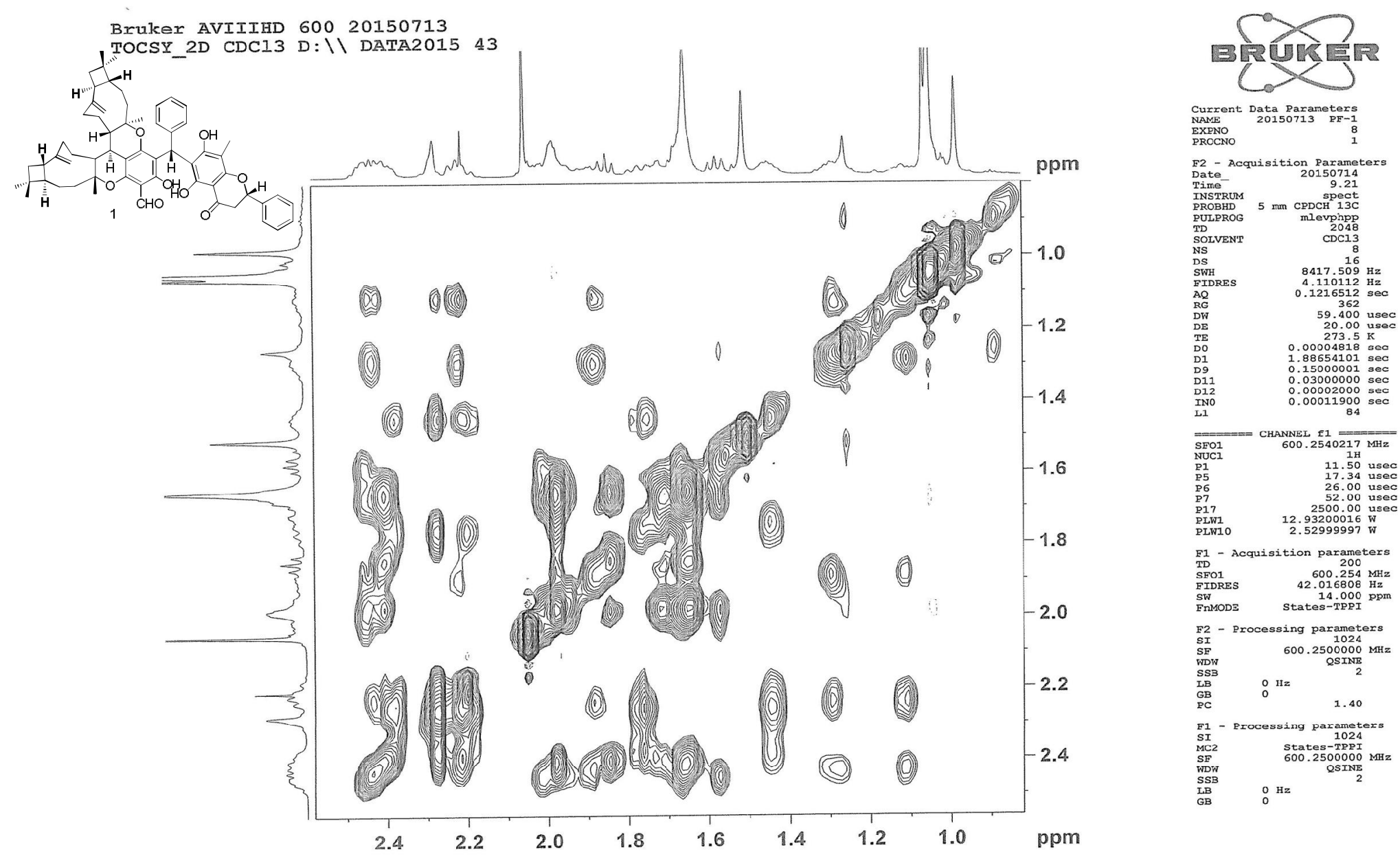
Figure S13. The ROESY spectrum of guajavadimer A (1) in $\mathrm{CDCl}_{3}$.

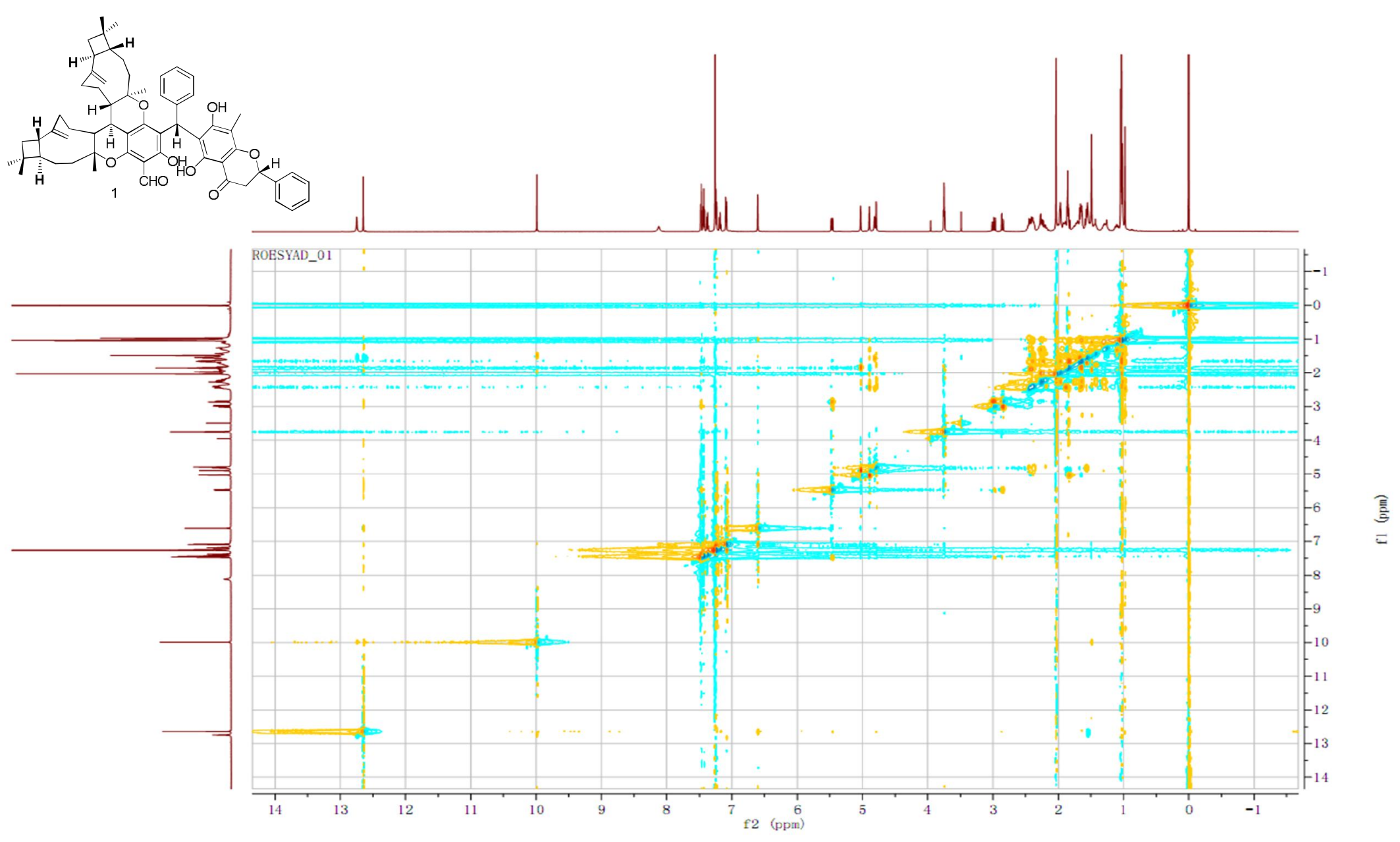


Figure S34. The ROESY spectrum of guajavadimer A (1) in $\mathrm{CDCl}_{3}(600 \mathrm{MHz})$

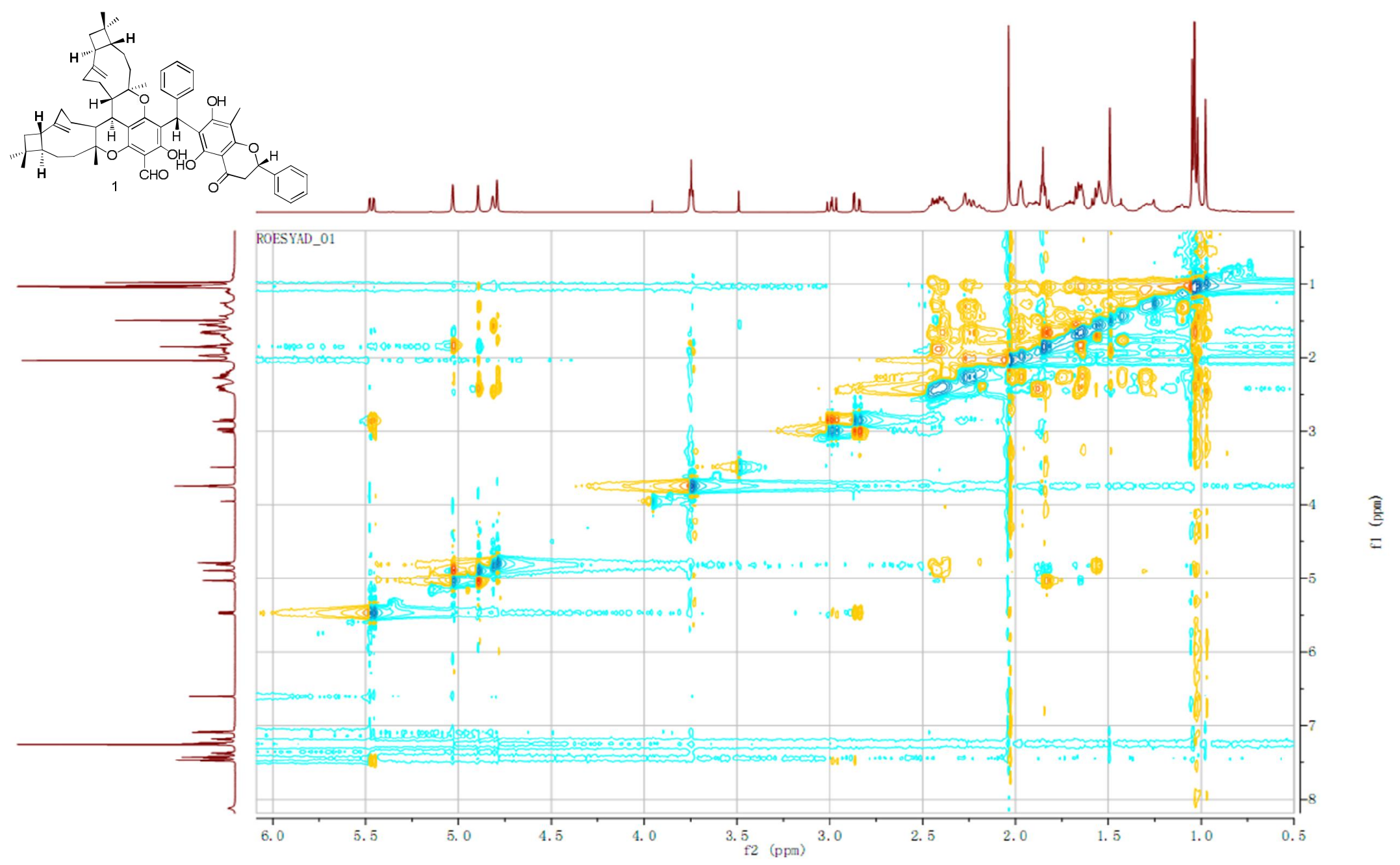


Figure S35. The ROESY spectrum of guajavadimer A (1) in $\mathrm{CDCl}_{3}(600 \mathrm{MHz})$.

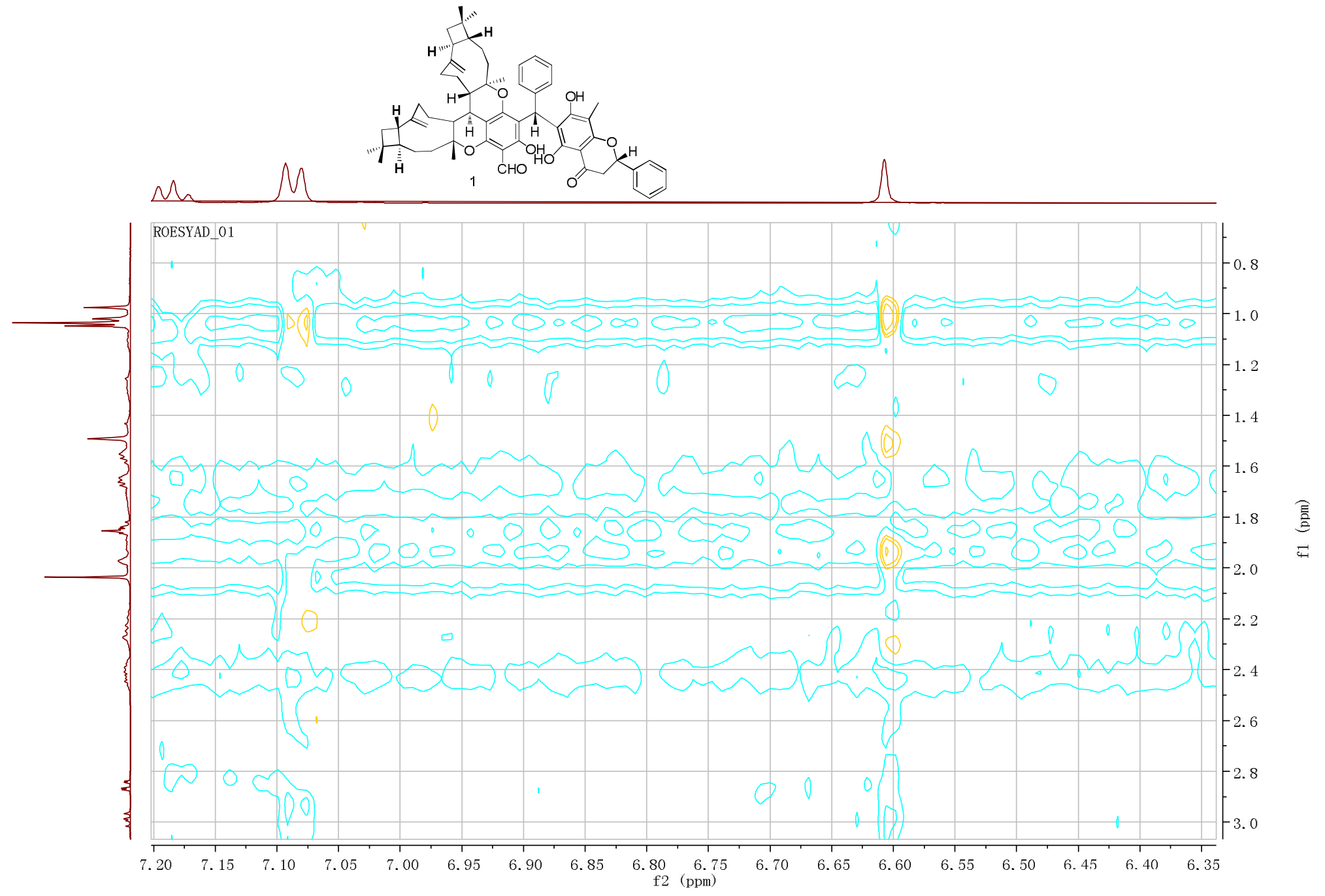


Figure S36. The 1D-TOCSY spectrum of guajavadimer A (1) in $\mathrm{CDCl}_{3}(600 \mathrm{MHz})$

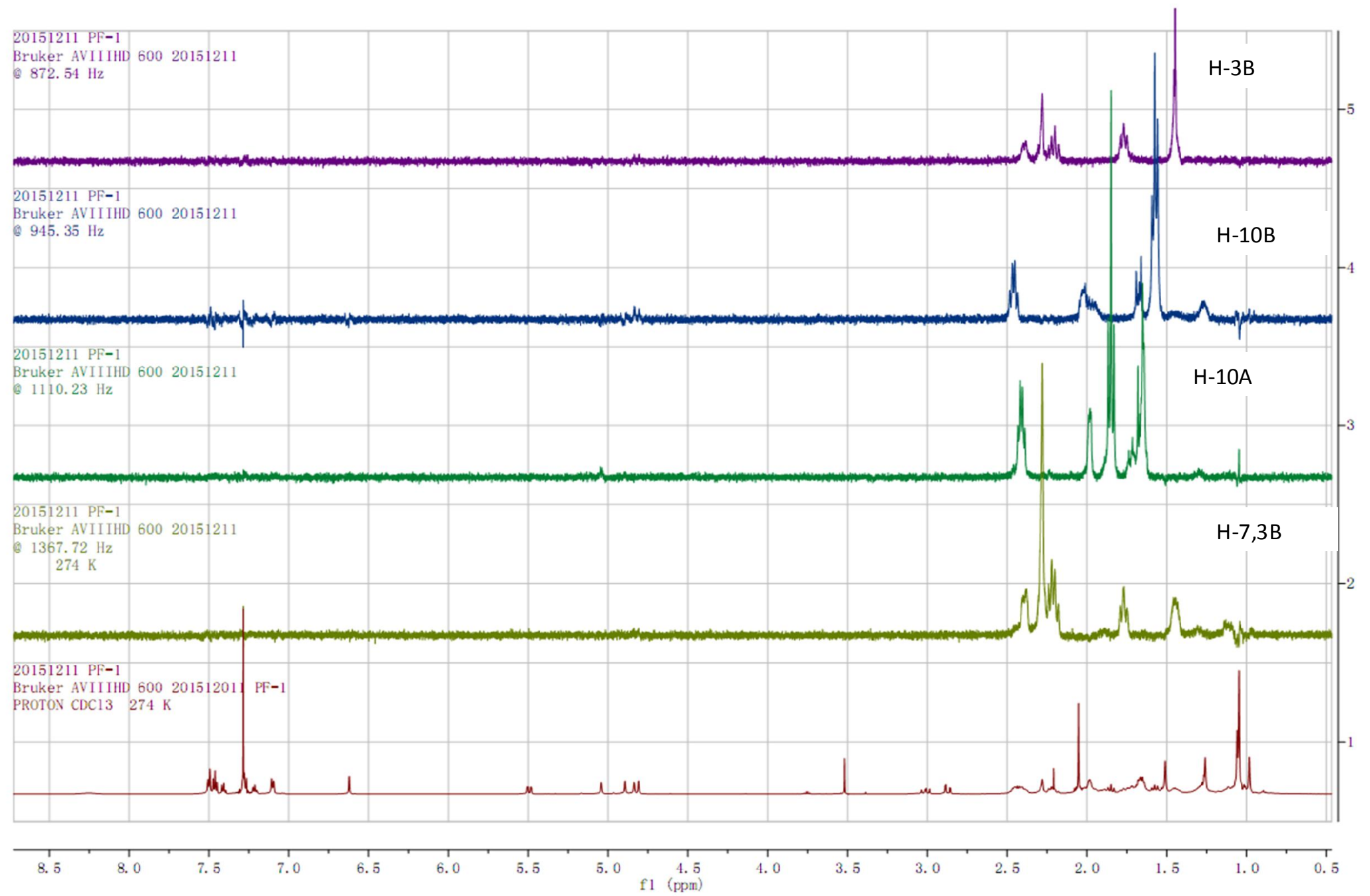


Figure S37. The 1D-TOCSY spectrum of guajavadimer A (1) in $\mathrm{CDCl}_{3}(600 \mathrm{MHz})$

Bruker AVIIIHD 60020151211

C $872.54 \mathrm{~Hz}$

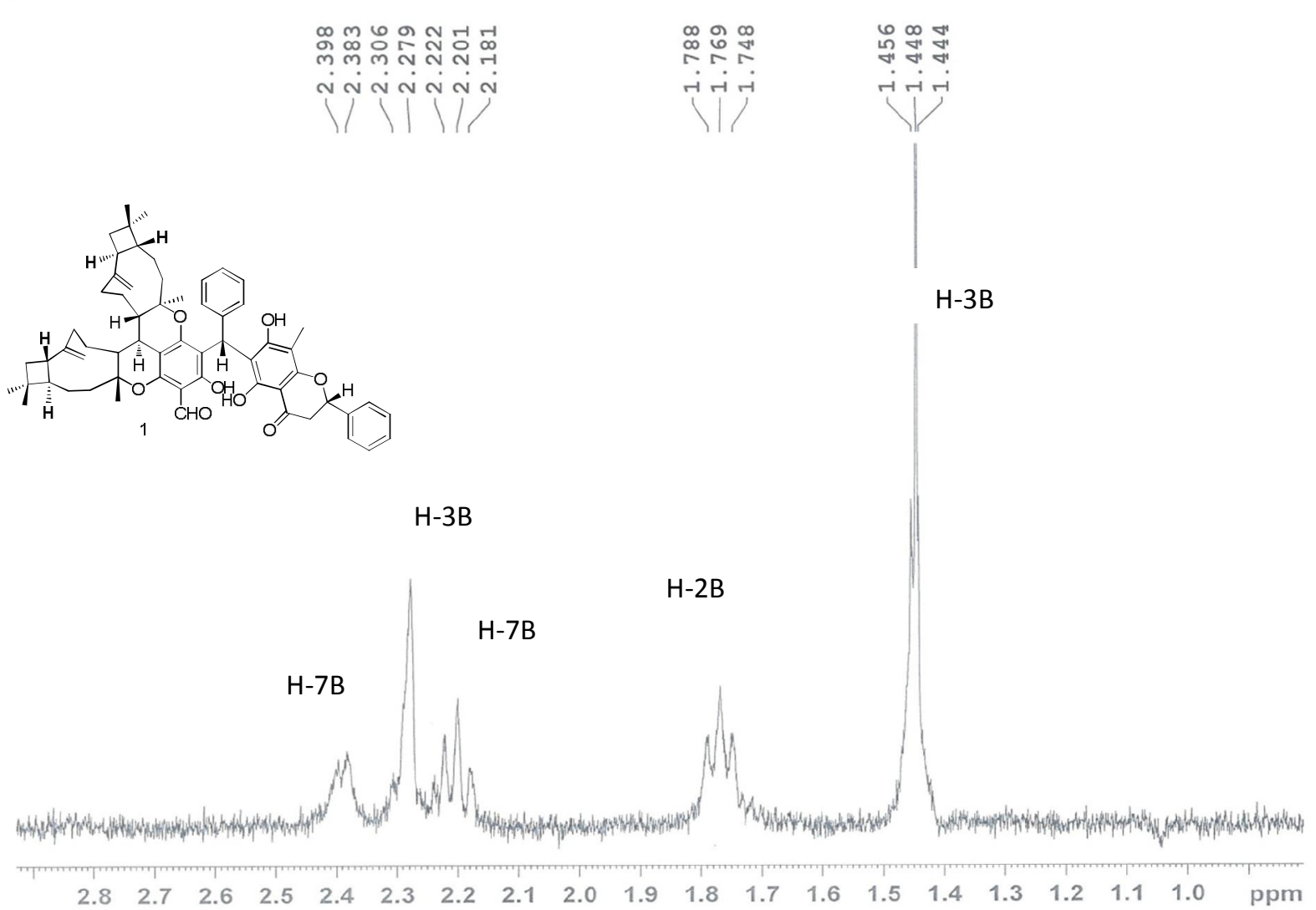

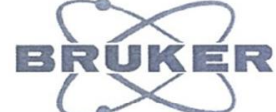

Current Data Parameters
NAME $20151211 \mathrm{PF}-1$
EXPNO
PXPOCNO

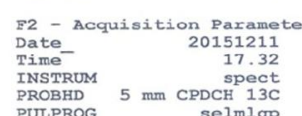

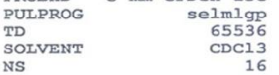

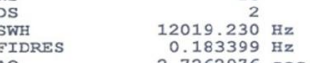

\begin{tabular}{rr}
$\mathrm{AQ}$ & $2.7262976 \mathrm{sec}$ \\
$\mathrm{RG}$ & 2050 \\
$\mathrm{NW}$ & $41.600 \mathrm{usec}$ \\
\hline
\end{tabular}

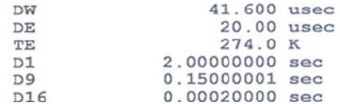

T1

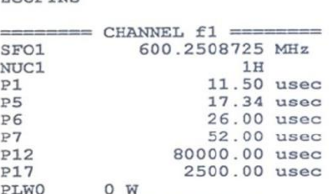

L 17 w 2500.00 us

2.52999997

SPOAL2
SPOFFS2
SPW2

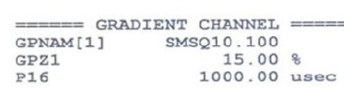

F2 - Processing parameters

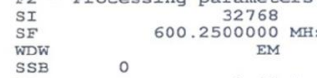


Figure S38. The 1D-TOCSY spectrum of guajavadimer A (1) in $\mathrm{CDCl}_{3}(600 \mathrm{MHz})$

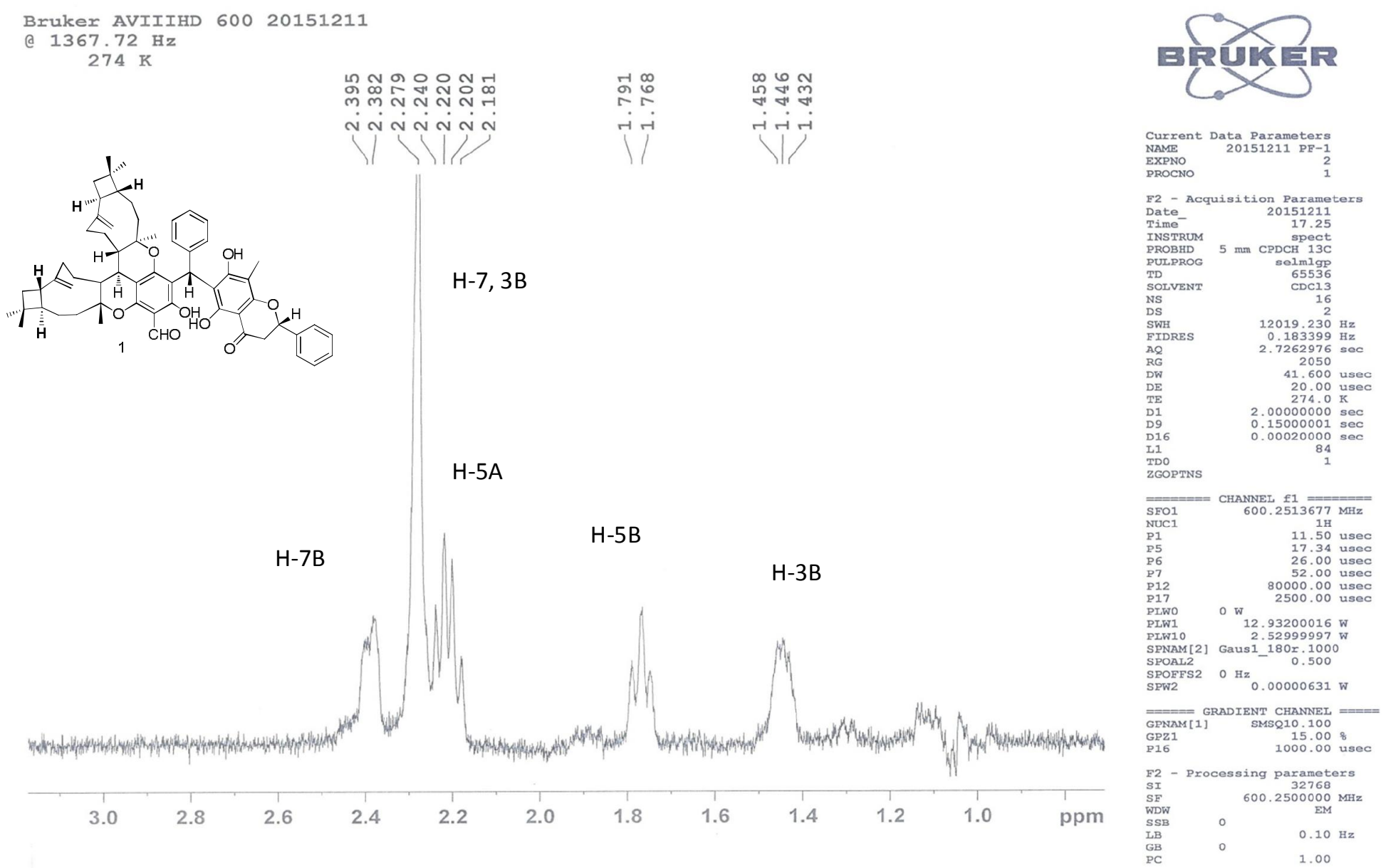


Figure S39. The 1D-TOCSY spectrum of guajavadimer A (1) in $\mathrm{CDCl}_{3}(600 \mathrm{MHz})$

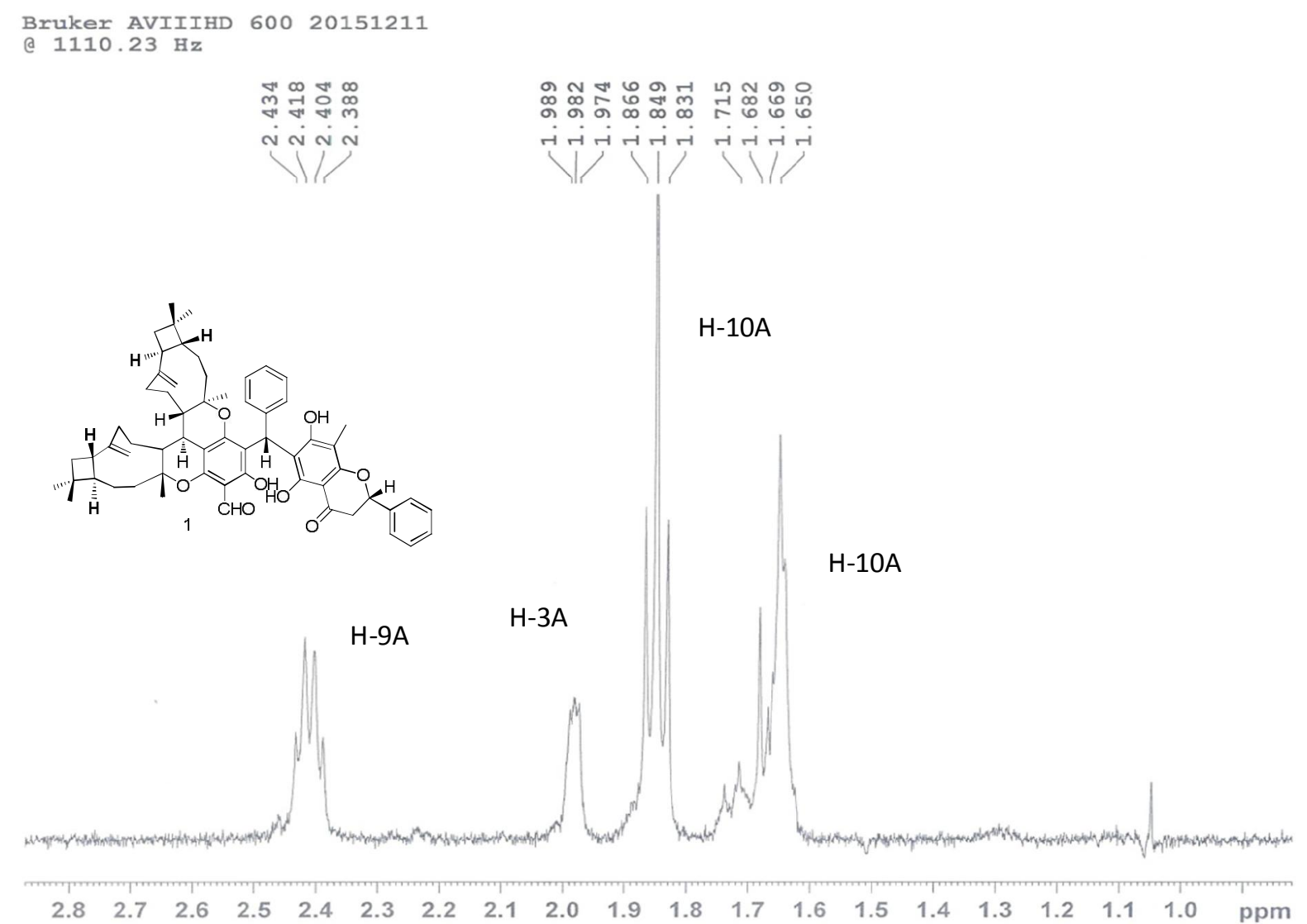

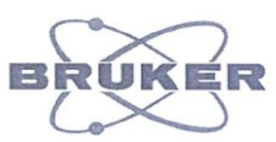

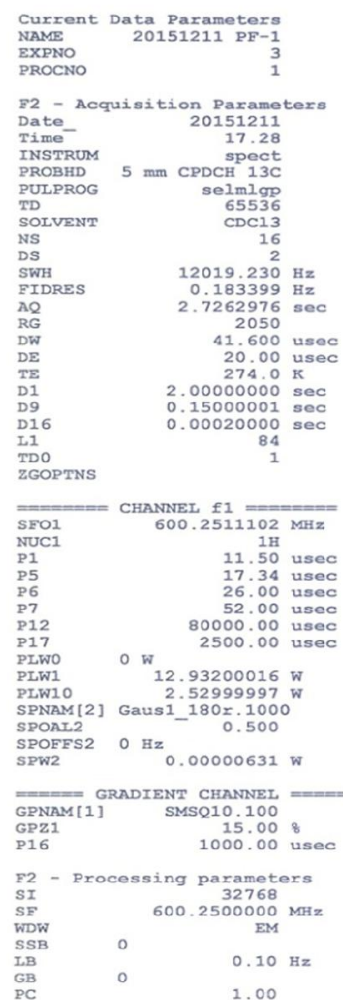


Figure S40. The 1D-TOCSY spectrum of guajavadimer A (1) in $\mathrm{CDCl}_{3}(600 \mathrm{MHz})$

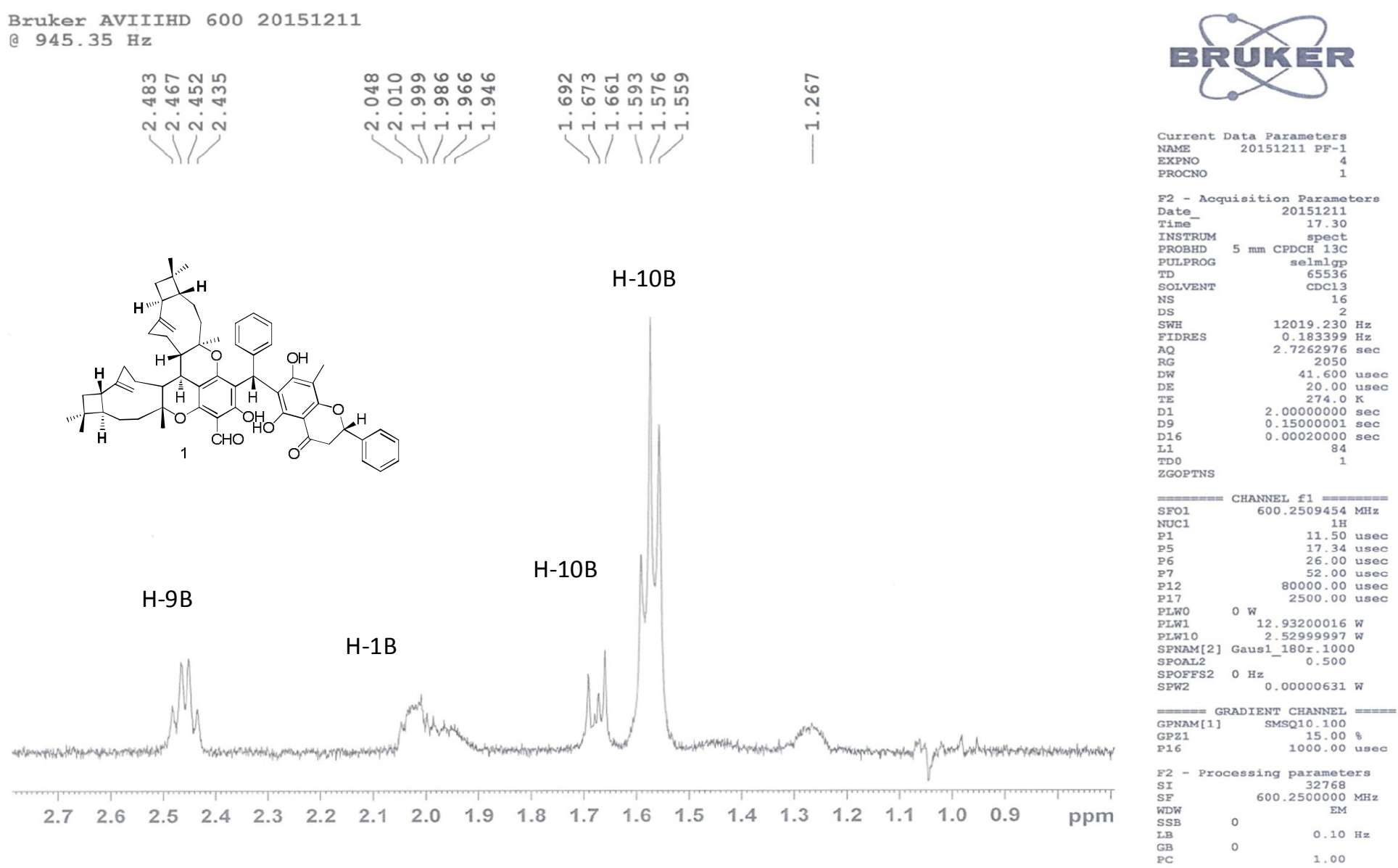

